\title{
EXPANSIÓN Y REESTRUCTURACIÓN DEL PARQUE RESIDENCIAL DEL PAÍS VASCO (1991-2011). CONSOLIDACIÓN DE PATRONES PROPIOS DE LA DISPERSIÓN URBANA
}

\author{
Roberto Torres Elizburu \\ Departamento de Geografía, Prehistoria y Arqueología. \\ Universidad de País Vasco UPV/EHU \\ roberto.torres@ehu.eus
}

\section{RESUMEN}

En la Comunidad Autónoma del País Vasco la expansión inmobiliaria no alcanzó la intensidad de otras regiones españolas pero estuvo muy por encima del tenue crecimiento demográfico. Mediante la Estadística Municipal de Vivienda de Eustat se analiza la evolución del parque residencial vasco entre 1991 y 2011: el incremento del volumen de viviendas, las transformaciones en las tipologías y en el uso, así como las pautas territoriales y temporales durante el periodo. Se constatará el considerable despegue inmobiliario de los años pasados, que se propagó por todo el territorio vasco bajo diferentes formas.

Palabras clave: País Vasco, vivienda, parque residencial, boom inmobiliario, dispersión urbana.

\section{ABSTRACT}

In the Autonomous Community of the Basque Country the real-estate dynamism did not reach the intensity of other Spanish regions, but it was clearly superior to demographic growth. Using Municipal Housing Statistics of Basque Statistic Organism (Eustat) we will analyze the evolution of the housing stock between 1991 and 2011: increase in housing

Fecha de recepción: septiembre 2014

Fecha de aceptación: junio 2015. 
numbers, transformations in building types and use, as well as territorial and temporary patterns of the period. The real-estate takeoff was considerable over the last years and urban growth has spread throughout the Basque territory under different forms.

Keywords: Basque Country, housing, housing stock, real estate bubble, urban sprawl.

\section{INTRODUCCIÓN}

El estudio de la vivienda en España fue cobrando relevancia en los primeros años del nuevo siglo, a medida que se evidenciaba la desproporcionada actividad edificatoria durante el periodo del boom inmobiliario que culminó en el año 2007. Distintos autores alertaron sobre lo desmesurado del desarrollo español, donde se edificaban anualmente más viviendas que en Francia y Alemania juntas, a pesar de que estos dos países concentrasen tres veces más población y presentaran mayor crecimiento demográfico que España (Naredo, 2004). La magnitud del sector de la construcción español en 2006 se podía resumir con estas cifras: la producción inmobiliaria de España superaba las veinte viviendas por cada mil habitantes, mientras que en Francia u Holanda se situaba por debajo de ocho y en Alemania era tan solo de cinco (Gaja, 2008).

A diferencia de otros ciclos inmobiliarios expansivos que afectaron al país en el pasado y que respondieron a una necesidad real de viviendas, el que arrancó a finales de la década de 1990 estaba caracterizado por su desconexión respecto a la dinámica demográfica (Nel·lo, 2004; García y Gutiérrez, 2007; Ferrán, 2011). La emancipación de las generaciones nacidas durante el baby boom, la reducción del tamaño medio de los hogares o la inmigración extranjera no resultaban suficientes para explicar la demanda de vivienda de aquellos años; para entender su dimensión hay que tener en cuenta la coyuntura especulativa que convirtió la vivienda en objeto de inversión por sus expectativas de revalorización a corto plazo (Muñiz at al., 2007; Mata, 2007). La demanda era respondida de forma solvente por muchos ayuntamientos, aprobando nuevos planes urbanísticos con propuestas de enorme dimensión que ni se molestaban en justificar y recordaban a los planes ultradesarrollistas de los años 60 (Burriel, 2008). De tal manera que el sector inmobiliario cobró un peso desproporcionado dentro de la economía española (Palacios, 2008; Romero, 2010; Fernández y Cruz, 2011) y el urbanismo pasó a convertirse en la principal fuente de financiación en muchos municipios (Sánchez y Suárez, 2008), con lo que el planeamiento va distanciándose de su concepción de función pública para convertirse en negocio.

En pocos años se constataron las consecuencias negativas que sobre el territorio acarreaba este modelo de crecimiento despilfarrador e insostenible, que conllevaba la artificialización acelerada de extensas superficies de suelo (Jiménez, 2011). Fue desdibujándose rápidamente el modelo de ciudad compacta tradicional por un nuevo patrón urbano más difuso, conformado por tejidos laxos y discontinuos alejados de los centros urbanos originarios, de modo que la dispersión urbana o urban sprawl cobra fuerza también en países mediterráneos. El hecho diferencial en España ha sido el corto periodo de tiempo que ha necesitado para consolidarse (Martori, 2010), al haber funcionado el fuerte auge inmobiliario que arrancó en la década de 1990 como detonante del cambio de trayectoria en los patrones de crecimiento urbano. 
La dispersión urbana responde a una amalgama de factores como la mejora de las infraestructuras de transporte, la difusión de la movilidad privada, el aumento del nivel de vida, la generalización de la segunda vivienda y el aprecio por modalidades residenciales de baja densidad en espacios abiertos. Las actuaciones públicas han jugado un papel importante en la rápida consolidación de modelos urbanos difusos a través de la construcción de carreteras de alta capacidad que atraen nuevos usos urbanos a espacios más distantes (Fernández, 2009). En el caso español, la Ley de Suelo de planteamiento liberal de 1998 pudo también favorecer la dispersión (Martori, 2010). Dado que nunca en la historia se ha dispuesto de mayor cantidad de leyes, normas y planes para el control de procesos territoriales agresivos, su generalización habría que achacarla a la descoordinación, al desgobierno territorial o a la corrupción asociada al urbanismo (Romero, 2010). No faltan voces que denuncian que esa misma pluralidad de normas facilita interpretaciones maleables y adaptables a las circunstancias e intereses particulares de cada caso (Delgado, 2008).

El fuerte crecimiento inmobiliario español alimentó la rápida consolidación de modelos urbanos dispersos, laxos y fragmentados, alcanzando especial relevancia en los entornos bajo la influencia de las áreas urbanas de Madrid (García y Gutiérrez, 2007; Naredo y Frías, 2007; Cebrián, 2007) y de Barcelona (Marmolejo y Stallbohm, 2008; Miralles, 2011). Otros estudios se han centrado en las expansiones urbanas de baja densidad (Font, 2007; Muñoz, 2008; Nel·lo, 2011), o en la invasión residencial de espacios rurales y naturales (Prados, 2006; Delgado, 2008; Borissova, 2007; Galdos y Ruiz, 2008). Estos trabajos ponen de manifiesto la dimensión que han cobrado esos procesos territoriales estrechamente vinculados al sobredimensionamiento del sector inmobiliario y de la construcción.

A pesar de las cifras indicadas al principio, la intensidad edificatoria en España encierra importantes contrastes regionales. El exhaustivo análisis de la envergadura del boom inmobiliario en las provincias españolas entre 1996 y 2006 realizado por Burriel (2008), pone de manifiesto que las tasas anuales de nueva vivienda más elevadas correspondían al litoral mediterráneo y a las provincias que rodean Madrid. Allí se localizaron los incrementos más acusados de la construcción, puesto que en ese intervalo se triplicó o incluso cuadriplicó el número de viviendas iniciadas al año. Dentro del contexto estatal, las tres provincias del País Vasco tuvieron un comportamiento moderado, puesto que frente a las 13,3 nuevas viviendas anuales por mil habitantes que se iniciaban de media en España, en Bizkaia y Gipuzkoa se construían 6,0 y 7,6 respectivamente, si bien Álava alcanzaba la media nacional con 13,4 . De modo que el dinamismo inmobiliario fue tenue en las dos provincias atlánticas, pero no en Álava, que con un peso demográfico menor que las otras dos, revelaba una considerable actividad.

En todo caso, en el conjunto del País Vasco el ciclo inmobiliario expansivo presentó una dimensión muy por debajo de la media estatal y su incidencia territorial fue menor en comparación con otras Comunidades Autónomas (Jiménez, 2011). Pese a la menor intensidad del despegue inmobiliario vasco, es necesario destacar la palpable desconexión del considerable aumento porcentual del número de viviendas respecto al tenue crecimiento demográfico (Altuzarra, 2012). Para entender las pautas espaciales de la vivienda será necesario tomar en consideración los flujos migratorios internos recientes (Torres, 2015; Galdos y Ruiz, 2011), así como la progresiva implantación de los planes territoriales de 
desarrollo de las Directrices de Ordenación Territorial de 1997. Sin olvidar que los nuevos desarrollos residenciales han estado a menudo condicionados por la limitada disponibilidad de suelos aptos para edificar, especialmente en los montuosos municipios de la vertiente atlántica que ya se encuentran densamente ocupados.

\section{OBJETIVOS, FUENTES Y METODOLOGÍA}

El trabajo tiene por objeto sacar a la luz la dinámica del parque residencial del País Vasco durante las dos últimas décadas; la evolución registrada en el número de viviendas, las transformaciones en las tipologías y en el uso, así como las pautas y tendencias territoriales entre 1991 y 2011, periodo que permite abarcar el último ciclo inmobiliario expansivo y durante el cual existe disponibilidad de fuentes estadísticas homologables. La investigación se plantea desde un enfoque geográfico que aborda el análisis territorial del parque vasco de viviendas, para descubrir el dinamismo y las transformaciones en función de una serie de variables espaciales como son el tamaño demográfico del municipio o su emplazamiento más o menos privilegiado dentro del sistema territorial. Diversos estudios realizados en la Comunidad Autónoma presentan formato de informe o diagnóstico (Rodríguez, 2001; Urrutia, 2006; Altuzarra, 2012), pero apenas otorgan relevancia al papel de esas variables geográficas.

Se han empleado los datos de vivienda publicados por el Instituto Vasco de Estadística (Eustat), que tienen su origen en la información de los Censos de Población y Viviendas de 1991, 2001 y 2011 y en las Estadísticas de Población y Viviendas de 1996 y 2006. Eustat reelabora esta información cruzándola con la proveniente de los registros administrativos de distintos departamentos y organismos del Gobierno Vasco; tras efectuar correcciones y ajustes resulta la Estadística Municipal de Viviendas referida a los citados años, la cual constituye la principal base del trabajo.

No obstante, diferentes autores advierten de las deficiencias de la información estadística sobre la vivienda, afectada por condicionantes que obstaculizan conocer esta realidad aparentemente objetiva en toda su dimensión y con el rigor que sería deseable (Vinuesa et al., 2008; Ferrán, 2011; Blanco et al., 2013). La inconsistencia de la información deriva de las dificultades para establecer una adecuada definición metodológica de cara a clasificaciones como el uso o el destino de la vivienda, así como de la poca frecuencia de los cómputos, que impiden disponer de información exacta y actualizada, especialmente relevante en momentos como el actual para conocer el alcance de problemas como el de la vivienda vacía.

El universo que aborda este trabajo es el de las viviendas familiares, para cuya definición los diferentes organismos alcanzan un consenso, al entenderla como un recinto estructuralmente independiente concebido para ser habitado por personas y cuyo uso es residencial, dejando fuera las que se encuentran en construcción o en ruina. Se considera vivienda principal cuando es utilizada toda o la mayor parte del año como residencia habitual. Precisamente es el parque de viviendas no principales (secundarias y vacías) el que presenta importantes deficiencias de información, puesto que su propia definición y delimitación conceptual es imprecisa y el procedimiento para su cómputo complejo y sujeto a apreciaciones arbitrarias (Vinuesa et al, 2008). Una vivienda familiar se considera secundaria o de temporada cuando es utilizada solo parte del año de forma estacional o esporádica y no constituye residencia habitual de una o varias personas, mientras que se considera desocupada o vacía cuando ni 
es residencia habitual ni es utilizada en los anteriores supuestos. Esta insuficiente precisión de los criterios para discriminarlas repercute en las deficiencias de su registro estadístico.

De tal forma que mientras la información sobre la vivienda principal se puede tomar como plenamente fiable, el cómputo de viviendas secundarias y vacías en el País Vasco arroja resultados diferentes en función de que el origen de la información sea INE, Eustat o el Observatorio Vasco de la Vivienda, que publica informes bianuales basados en muestreos mediante encuestas. En este trabajo se emplearán los datos recogidos en la referida Estadística Municipal de Viviendas de Eustat, porque presenta datos homologables entre las series temporales, así como con el resto de variables residenciales, si bien se tendrán presentes sus limitaciones.

Además de la intensidad de uso del parque residencial, se abordará también su estudio tipológico, considerando el número de viviendas del edificio con el fin de entrever las estructuras residenciales predominantes. Se ha procedido a clasificar las viviendas en función del número total de las que componen el edificio en el cual se alojan, agregando las nueve clases que recoge Eustat en tres categorías más operativas con los fines buscados: viviendas unifamiliares y bifamiliares, viviendas colectivas alojadas en bloque mediano-pequeño (3-10 viviendas) y viviendas colectivas en bloque grande ( $>11$ viviendas). En todo caso, el estudio estadístico se complementa con el trabajo de campo para el reconocimiento directo de las morfologías edificadas y percibir también aspectos como la intensidad de uso o el nivel de consolidación de diferentes entornos residenciales.

Para caracterizar las diferentes situaciones y dinámicas se desarrolla una metodología cuantitativa basada en operaciones estadísticas simples, de las que se obtendrán índices y tasas de crecimiento que permiten dimensionarlas, ubicarlas y reconocerlas. Con el fin de valorar los aspectos locacionales a los que se les supone un importante papel (la accesibilidad del municipio, su facilidad de conexión viaria o el tiempo de desplazamiento desde la capital), se ha recurrido a los indicadores sintéticos de transporte y movilidad del Sistema de Información Territorial Udalmap, clasificando los municipios en grupos. Igualmente, se analizará el comportamiento de las variables desde la perspectiva de la dimensión demográfica de los municipios, para entender así las dinámicas de diferentes tipos de asentamientos. La información obtenida a través de estos enfoques se recoge en cuadros y gráficas, acompañados de mapas coropléticos que a escala municipal reflejan las tendencias espaciales.

Se ha concedido atención a la evolución temporal de las variables ya que el intervalo 1991-2011 encierra altibajos importantes. A menudo se ha segmentado el extenso periodo en las dos décadas o en los cuatro quinquenios que lo componen siempre condicionados por los momentos del registro estadístico. La estadística de las licencias concedidas para viviendas de nueva planta recopilada desde hace poco más de una década por el Departamento de Vivienda, Obras Públicas y Transportes del Gobierno Vasco constituye una fuente de periodicidad anual, pero está limitada por la corta profundidad temporal de las series y un nivel de desagregación espacial insuficiente.

\section{CARACTERIZACIÓN DEL PARQUE RESIDENCIAL VASCO}

En un primer acercamiento al parque residencial vasco se conocerán sus características generales en cuanto a su intensidad de uso o su estructura, tomando como referencias las magnitudes del parque residencial español, pero resaltando al mismo tiempo la heteroge- 
neidad que encierra el País Vasco. La Comunidad Autónoma cuenta con una superficie de $7.234 \mathrm{~km}^{2}$ y una población de 2.179.815 habitantes en 2011, de lo que resulta una densidad de 301 habitantes $/ \mathrm{km}^{2}$. Esta elevada cifra media esconde importantes contrastes internos, ya que mientras Bizkaia casi la duplica, en Álava apenas se llega a la tercera parte. La estructura urbana también presenta diferentes situaciones, ya que la aglomeración urbana del Bilbao Metropolitano, que se articula como un continuo urbanizado en torno a la ría del Nervión, concentra casi tres cuartas partes de la población provincial, mientras que Gipuzkoa tiene una red urbana más equilibrada formada por ciudades de tamaño medio distribuidas en los principales valles. En Álava, la provincia menos poblada, Vitoria-Gasteiz concentra buena parte de la población y en el resto del territorio predominan los pueblos.

El espacio vasco se encuentra articulado por una tupida red de infraestructuras viarias que posibilitan un alto grado de accesibilidad a casi todos los rincones. Sin embargo, la constitución física del territorio presenta obstáculos para los asentamientos humanos, especialmente en la poblada vertiente atlántica de topografía montuosa, donde los espacios llanos se reducen a estrechos fondos de valle y a llanuras abiertas a la costa. En cuanto a la capacidad de acceso a la vivienda, el nivel medio de renta anual por hogar se sitúa un $24 \%$ por encima de la media estatal, si bien durante los años de fuerte crecimiento las tres capitales vascas ocupaban los puestos más altos en el listado de precios de la vivienda entre las ciudades españolas (Urrutia, 2006). Esto impulsó un papel activo por parte de las instituciones para promover la vivienda pública dirigida a colectivos menos favorecidos (Burón, 2005).

\section{III.1. Diferencias territoriales en la disponibilidad de vivienda y en la intensidad de uso}

El parque residencial del País Vasco, que en el año 2011 sobrepasaba el millón de viviendas familiares, muestra una distribución provincial desigual en consonancia con el reparto de la población (Cuadro 1). Bizkaia aloja algo más de la mitad de la población y de las viviendas de la Comunidad Autónoma (52,9\% y 52,0\%), si bien su peso demográfico y residencial han caído ligeramente. Gipuzkoa acoge alrededor de la tercera parte del contingente demográfico y residencial, mientras que Álava, la más extensa de las tres, tan solo representa el 14,7\% de la población y el 15,3\% del parque residencial. Estas dos últimas provincias han reforzado su peso en ambas variables, especialmente Álava, que ha ganado peso demográfico y residencial. Bizkaia, la más densamente poblada y que alberga el mayor espacio metropolitano, ha sufrido un tenue aligeramiento del peso demográfico y residencial a favor de las otras, especialmente de la provincia meridional beneficiada por espacios más descongestionados.

La tasa relativa de vivienda por mil habitantes es de 467,4, sin grandes contrastes entre las tres provincias, si bien Bizkaia presenta la disponibilidad más restringida frente a la mayor de Álava, al encontrarse la variable relacionada con el peso de la vivienda no principal. En todo caso, a lo largo de las dos últimas décadas han tenido lugar dos procesos simultáneos: un considerable aumento de la tasa de vivienda por mil habitantes, así como una intensificación del uso del parque residencial al haber aumentado 3,2 puntos porcentuales el peso de la principal.

La ratio de viviendas por mil habitantes del País Vasco es sensiblemente inferior a la estatal, puesto que el peso de la vivienda no principal tiene menor entidad. Concurren varios factores, por un lado el mayor grado de urbanización de la sociedad vasca, que favorece 
una ocupación más intensiva del parque de viviendas, y por el otro, la reducida envergadura territorial y la alta densidad demográfica, que se traduce en una escasa capacidad de acogida de viviendas secundarias. Como consecuencia, el parque residencial vasco presenta la mayor tasa de ocupación permanente de todo el estado (Altuzarra, 2012). La tendencia entre las familias vascas ha sido adquirir segundas viviendas en Comunidades limítrofes, tal y como se deduce del importante incremento registrado por este tipo de residencias en Cantabria, Navarra o La Rioja (Oliver, 2005).

Cuadro 1

POBLACIÓN Y PARQUE RESIDENCIAL 1991 Y 2011, POR TERRITORIOS

\begin{tabular}{|c|c|c|c|c|c|c|c|c|c|}
\hline \multirow[b]{3}{*}{ Álava/Araba } & \multicolumn{3}{|c|}{ Población } & \multicolumn{2}{|c|}{ Número de viviendas familiares } & \multicolumn{2}{|c|}{$\begin{array}{c}\text { Tasa de } \\
\text { viviendas por } \\
1000 \text { hab. }\end{array}$} & \multicolumn{2}{|c|}{$\begin{array}{c}\text { Peso } \\
\text { vivienda } \\
\text { principal }(\%)\end{array}$} \\
\hline & 1991 & & 2011 & 1991 & 2011 & 1991 & 2011 & 1991 & 2011 \\
\hline & 272.447 & 12,9 & $321.254 \quad 14,7$ & $105.647 \quad 13,7$ & $156.273 \quad 15,3$ & 387,8 & 486,4 & 77,4 & 83,3 \\
\hline Bizkaia & 1.155 .106 & 54,9 & $1.153 .351 \quad 52,9$ & $423.686 \quad 54,8$ & $529.686 \quad 52,0$ & 366,8 & 459,3 & 82,2 & 85,7 \\
\hline Gipuzkoa & 676.488 & 32,2 & $705.210 \quad 32,4$ & $244.282 \quad 31,6$ & $332.835 \quad 32,7$ & 361,1 & 472,0 & 81,5 & 83,0 \\
\hline País Vasco & 2.104 .041 & 100 & $2.179 .815 \quad 100$ & $773.615 \quad 100$ & $1.018 .794 \quad 100$ & 367,7 & 467,4 & 81,3 & 84,5 \\
\hline España & 38.872 .268 & & 46.815 .916 & 17.206 .363 & 25.208 .623 & 442,6 & 538,5 & 68,2 & 71,7 \\
\hline
\end{tabular}

Fuente: Eustat, INE. Elaboración propia.

Pero el promedio vasco de 467,4 viviendas por mil habitantes encierra contrastes territoriales condicionados por la dimensión demográfica del municipio, así como por su accesibilidad más o menos propicia (Cuadro 2). La tasa guarda una relación inversa con el tamaño de los asentamientos, de manera que en los municipios de menor entidad sobrepasa las 560,0 viviendas por mil habitantes, disminuyendo paulatinamente en los siguientes grupos hasta los de 40.001-100.000 habitantes donde se registra el menor valor (436,7). La tendencia se repite a la luz de las condiciones de accesibilidad de los municipios, puesto que los que disfrutan de un emplazamiento privilegiado con buenas conexiones presentan la tasa más comedida, que va creciendo conforme las condiciones empeoran hasta alcanzar el mayor valor en los municipios excéntricos, donde la tasa de viviendas por residentes es la más alta del País Vasco.

La explicación está en el grado de ocupación del parque residencial de cada entorno; los municipios pequeños de mayor excentricidad destacan por el peso de las viviendas no principales, por lo que la tasa de disponibilidad resulta mayor. A medida que aumenta el tamaño de los asentamientos y mejoran las condiciones de accesibilidad, la participación de la vivienda principal aumenta, disminuyendo así la ratio. La vivienda secundaria presenta mayor querencia hacia municipios pequeños y periféricos, situados en entornos descongestionados con paisajes naturales o costeros afines con valores recreativos y de ocio (municipios del litoral, Urdaibai, Valles Alaveses o Rioja Alavesa). Pero la vivienda desocupada no muestra tendencias espaciales tan nítidas por las complejas vicisitudes que esconde (Rodríguez, 2001; Vinuesa et al., 2008). El reconocimiento sobre el terreno revela que en los municipios 
excéntricos corresponden en su mayoría con viviendas de elevada edad media y deficientes condiciones de habitabilidad, mientras que en ámbitos más urbanos destacan las viviendas en venta o las adquiridas con un fin diferente al de uso.

Cuadro 2

TASA DE VIVIENDA DISPONIBLE (n viv./1000 hab.) Y DISTRIBUCIÓN PORCENTUAL SEGÚN USO (\%) EN DIFERENTES EMPLAZAMIENTOS DEL PAÍS VASCO, 2011

\begin{tabular}{|c|c|c|c|c|c|c|c|c|c|c|c|}
\hline \multicolumn{6}{|c|}{ En municipios clasificados por dimensión demográfica } & \multicolumn{6}{|c|}{ En municipios clasificados por condiciones de accesibilidad } \\
\hline & & $\begin{array}{c}\text { Viv./1000 } \\
\text { hab. }\end{array}$ & $\begin{array}{l}\text { Princi- } \\
\text { pales }\end{array}$ & $\begin{array}{l}\begin{array}{l}\text { Secun- } \\
\text { darias }\end{array} \\
\end{array}$ & $\begin{array}{c}\text { Desocu- } \\
\text { padas }\end{array}$ & & & $\begin{array}{c}\text { Viv./1000 } \\
\text { hab. }\end{array}$ & $\begin{array}{l}\text { Princi- } \\
\text { pales }\end{array}$ & $\begin{array}{l}\text { Secun- } \\
\text { darias }\end{array}$ & $\begin{array}{c}\text { Desocu- } \\
\text { padas }\end{array}$ \\
\hline$<2.500$ hab. & $(161)$ & 560,0 & 67,7 & 14,7 & 17,6 & Muy Alta & (44) & 454,8 & 87,4 & 2,6 & 10,0 \\
\hline $2.501-5.000$ & $(27)$ & 490,5 & 77,5 & 7,9 & 14,6 & Alta & $(47)$ & 473,7 & 80,2 & 7,1 & 12,7 \\
\hline $5.001-10.000$ & $(24)$ & 464,4 & 82,6 & 5,5 & 11,9 & Media & $(58)$ & 479,3 & 83,6 & 4,2 & 12,2 \\
\hline $10.001-20.000$ & (21) & 463,7 & 82,9 & 4,8 & 12,2 & Baja & $(60)$ & 490,1 & 79,1 & 5,7 & 15,2 \\
\hline $20.001-40.000$ & $(8)$ & 447,5 & 87,1 & 2,0 & 10,9 & Muy Baja & (42) & 614,0 & 63,8 & 19,8 & 16,4 \\
\hline $40.001-100.000$ & (6) & 436,7 & 89,5 & 1,6 & 8,9 & & & & & & \\
\hline$>100.000$ & (4) & 466,0 & 87,6 & 2,2 & 10,2 & País Vasco & (251) & 467,4 & 84,5 & 4,1 & 11,4 \\
\hline
\end{tabular}

Fuente: Eustat, Udalmap. Elaboración propia.

*Entre paréntesis se indica el número de municipios acogidos en cada categoría.

Tanto en las capitales de provincia como en los municipios colindantes que forman parte de su espacio metropolitano, así como en los corredores más densamente urbanizados con tradición industrial, el parque residencial se caracteriza por la alta tasa de ocupación continuada, ya que el peso de la vivienda principal raramente desciende del $85 \%$, caso de comarcas como Gran Bilbao, Donostialdea, Duranguesado o Alto Deba. En Álava esta situación se restringe a la capital Vitoria-Gasteiz y a los dos únicos municipios que superan el umbral de los 10.000 habitantes (Laudio/Llodio y Amurrio), puesto que el resto del territorio alavés presenta un carácter más rural y la intensidad del uso continuado de la vivienda desciendo considerablemente, al igual que ocurre en las comarcas periféricas de menor peso industrial de las provincias atlánticas, caso de Gernika-Bermeo, Encartaciones o Goierri.

\section{III.2. Coexistencia de distintos entornos residenciales con dinámicas demográficas contrastadas}

El modelo edificatorio vasco es claramente plurifamiliar y se posiciona a la cabeza de todas las Comunidades Autónomas en cuanto al peso de la vivienda alojada en bloque (Altuzarra, 2012), ya que la fuerte demanda residencial durante el desarrollismo fue respondida mediante la edificación en altura por la escasez de suelo en los valles más dinámicos (Rodríguez, 2001). Sin embargo, en el País Vasco conviven situaciones dispares (Figura 1). En los municipios de carácter urbano que se desarrollaron durante los años de fuerte industrialización el peso de las viviendas alojadas en bloque plurifamiliar supera el 85\%, de manera que sobre el mapa conforman un arco que se extiende desde la comarca del Gran Bilbao hasta Donostialdea, articulado a grandes rasgos alrededor de la carretera N-634 y la autovía A-8. Más distanciados de esos ejes, los municipios de alto peso industrial de la comarca de Alto Deba y los situados en el corredor de la carretera N-1 a su paso por Tolosaldea y Goierri también albergan altas densidades. 
Álava vuelve a manifestar una realidad espacial polarizada, ya que los asentamientos netamente urbanos se restringen además de a la propia capital, a los otros tres municipios que superan los 5.000 habitantes. En el resto del territorio alavés, así como en las comarcas atlánticas periféricas que permanecieron al margen de la industrialización, predomina un parque residencial de menores densidades donde la vivienda unifamiliar sigue siendo la protagonista; es el caso de Encartaciones, Gernika-Bermeo o los municipios encarados en laderas menos accesibles de las comarcas guipuzcoanas de Tolosaldea y Goierri.

Figura 1

PESO PORCENTUAL DE LA VIVIENDA COLECTIVA, 2011

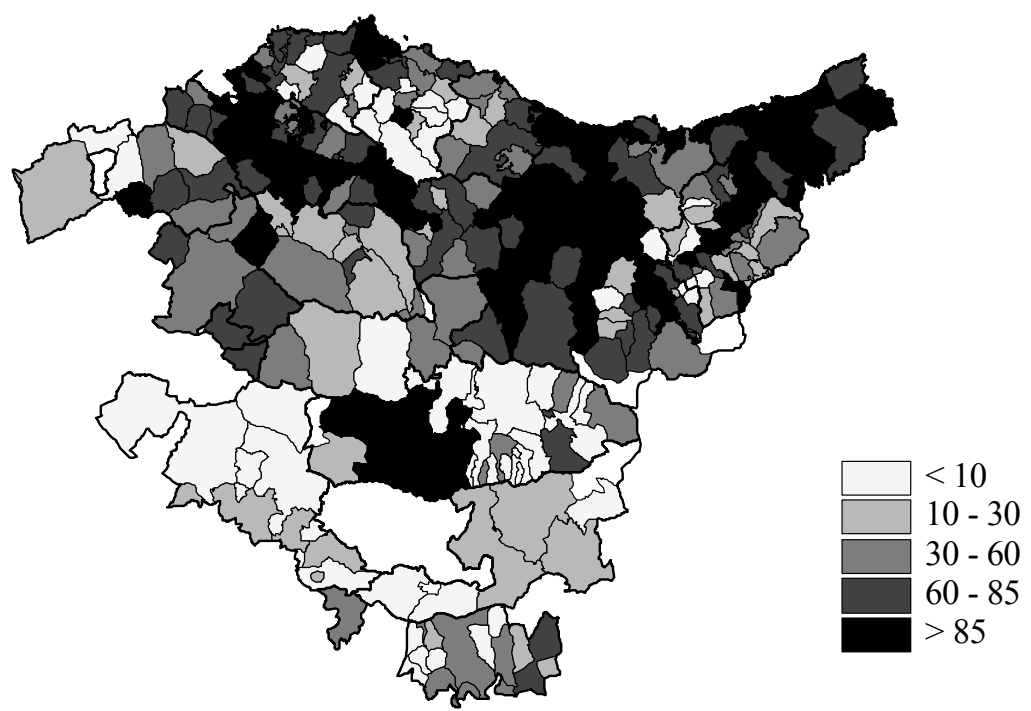

Fuente: Eustat. Elaboración propia.

El emplazamiento más o menos privilegiado respecto a los centros y corredores de actividad del País Vasco, así como la dimensión demográfica, condicionan la tipología edificatoria. En los municipios de menos de 2.500 habitantes más de la mitad de las viviendas son unifamiliares y bifamiliares, mientras que las colectivas tienden a alojarse en bloques de pequeña dimensión (Cuadro 3). Por encima de ese umbral desciende drásticamente la participación de la vivienda unifamiliar, que no alcanza ni la quinta parte en el siguiente grupo, aminorando su presencia hasta situarse por debajo del 5\% en los municipios de más de 40.000 habitantes. Así, conforme aumenta el tamaño del municipio cobra mayor protagonismo la vivienda colectiva; si en los municipios de 2.501-5.000 habitantes la vivienda colectiva se aloja a partes iguales en bloques pequeños y grandes, a medida que aumenta el tamaño del asentamiento cobra importancia el bloque plurifamiliar grande, donde se ubican prácticamente el $80 \%$ de las viviendas de las capitales.

Un aspecto vital para entender las dinámicas inmobiliarias recientes lo pone de manifiesto la estrecha relación entre el contexto residencial y el atractivo demográfico (Cuadro 
3). Mientras los municipios menores de 10.000 habitantes han registrado saldos migratorios internos positivos de entidad inversamente proporcional al tamaño demográfico, los situados por encima de ese umbral han sufrido pérdidas de residentes. Sale a la luz el patrón migratorio reciente según el cual se ha consolidado un nuevo flujo migratorio originado en los entornos más poblados y urbanizados con destino a municipios menores caracterizados por menores densidades (Torres, 2015).

Cuadro 3

COMPOSICIÓN DEL PARQUE RESIDENCIAL Y VARIABLES DEMOGRÁFICAS EN MUNICIPIOS CLASIFICADOS POR DIMENSIÓN DEMOGRÁFICA

\begin{tabular}{|l|c|c|c|c|c|}
\hline \multirow{2}{*}{} & \multicolumn{3}{|c|}{ Composición tipológica en 2011 (\%) } & \multicolumn{2}{c|}{$\begin{array}{c}\text { Variables demográficas, } \\
1991-2011\end{array}$} \\
\cline { 2 - 6 } & $\begin{array}{c}\text { Unifamiliares } \\
\text { y } \\
\text { bifamiliares }\end{array}$ & $\begin{array}{c}\text { Vivienda } \\
\text { en bloque } \\
\text { mediano } \\
(3-10 \text { viv. })\end{array}$ & $\begin{array}{c}\text { Vivienda } \\
\text { en bloque } \\
\text { grande } \\
(>11 \text { viv. })\end{array}$ & $\begin{array}{c}\text { Saldo } \\
\text { migratorio int. } \\
\text { medio anual } \\
(\%)\end{array}$ & $\begin{array}{c}\text { Evolución de } \\
\text { la población } \\
1991-2011 \\
(\%)\end{array}$ \\
\hline$<2.500$ hab. & 55,5 & 29,8 & 14,6 & 6,6 & 26,9 \\
$2.501-5.000$ & 19,9 & 39,9 & 40,2 & 3,7 & 16,4 \\
$5.001-10.000$ & 14,2 & 41,0 & 44,7 & 2,5 & 11,3 \\
$10.001-20.000$ & 8,6 & 38,7 & 52,6 & $-1,0$ & 3,2 \\
$20.001-40.000$ & 5,3 & 29,0 & 65,7 & $-1,1$ & $-3,0$ \\
$40.001-100.000$ & 4,6 & 29,9 & 65,6 & $-1,6$ & $-4,7$ \\
$>100.000$ & 2,9 & 17,6 & 79,5 & $-0,8$ & 2,3 \\
\hline País Vasco & 10,5 & 27,7 & 61,7 & 0,0 & 3,6 \\
\hline
\end{tabular}

Fuente: Eustat. Elaboración propia.

En los últimos años se ha manifestado una tendencia a abandonar núcleos saturados y congestionados afectados por desorden urbano o problemas de contaminación ambiental. Otros municipios de antigua urbanización con limitaciones para acometer expansiones residenciales al ubicarse en valles con escasas superficies aptas o prácticamente ocupados, han perdido población. La merma más notable corresponde a los municipios de 40.001-100.000 habitantes, donde se encuadran Arrasate/Mondragón, Eibar, Sestao, Errenteria, Basauri, Santurtzi o Portugalete, municipios que hasta la década de 1970 funcionaron como importantes receptores de población pero en los que la tendencia ha revertido.

Por el contrario, el incremento demográfico más acusado ha radicado en los municipios de menos de 2.500 habitantes, donde la población ha crecido un $26,9 \%$, seguido con cifras más moderadas por los siguientes grupos. La desconcentración de la población ha beneficiado a los municipios menores, que se han reforzado como nuevos emplazamientos residenciales al disponer de suelo potencialmente urbanizable para acoger expansiones que no tienen cabida en muchos centros urbanos tradicionales. Durante los años de ciclo económico expansivo se ha ofertado allí vivienda a precio más razonable que en los entornos de mayor centralidad y además, la revalorización social de modalidades residenciales 
alternativas, la llamada «moda del adosado» y la querencia por hábitats ambientalmente privilegiados han dirigido la demanda hacia municipios menores con usos del suelo más extensivos. Estas nuevas pautas residenciales han trastocado las lógicas espaciales antiguas, de forma que las grandes áreas urbanas de las provincias atlánticas han perdido población joven, mientras las comarcas que las bordean, Plentzia-Mungia, Urola-Costa, Tolosaldea y Estribaciones del Gorbea, presentan los mayores índices de juventud (Luxán y Martín, 2012), puesto que ahí ha conformado su hogar una parte de la generación nacida durante el baby boom. Al mismo tiempo, otros pequeños municipios más periféricos pero con amenidades ambientales han conocido la llegada de adultos de mediana edad y elevado nivel de renta que han ocupado allí nuevas viviendas (Torres, 2015).

\section{CAMBIOS EN EL PARQUE RESIDENCIAL ENTRE 1991 Y 2011}

El ciclo inmobiliario expansivo, la paulatina implementación de los instrumentos de ordenación territorial, los patrones recientes de movilidad o la generalización de pautas culturales tendentes a la revalorización de entornos o modalidades alternativas, han acarreado importantes transformaciones del parque residencial vasco. En este capítulo se profundizará en el análisis espacial de las dinámicas residenciales y en las transformaciones en cuanto a tipologías y usos.

\section{IV.1. Incremento de viviendas y reconfiguración territorial de la función residencial}

El número de viviendas familiares en el País Vasco ha aumentado un 31,7\% entre 1991 y 2011, magnitud situada por debajo de la estatal que fue del 46,5\%. Sin embargo es preciso destacar que durante el mismo periodo la población vasca aumentó tan solo un 3,6\%, mientras que la española lo hizo un 20,4\%, lo que revela un considerable desajuste entre la variable demográfica y la inmobiliaria en el caso vasco. A pesar de constatarse la vinculación entre el dinamismo constructivo y el incremento demográfico (cuadro 3), destaca la importante amplitud en la dimensión de ambas variables, lo que resulta sintomático del expansionismo del periodo. Si bien durante los primeros años la demanda de viviendas respondía en mayor medida al componente demográfico, fruto de la emancipación de una cohorte numerosa, durante los años posteriores fueron cobrando relevancia factores socioculturales relacionados con la reducción del tamaño familiar y las nuevas pautas culturales y de ocio (Oliver, 2005; Luxán y Martín, 2012). Como consecuencia el desfase entre la variable demográfica y la residencial fue acentuándose conforme se consolidaba aquel contexto social proclive al desarrollo inmobiliario.

Pero este dinamismo encierra situaciones dispares, dado que Álava ha sido la provincia más desarrollista $(47,9 \%)$ y alcanza una intensidad que supera ligeramente la media nacional (Cuadro 4). Bizkaia con algo más de la mitad del parque residencial vasco, muestra el crecimiento relativo más moderado $(25,0 \%)$, si bien hay que tener presente que en términos absolutos ha acaparado el mayor volumen de nueva vivienda. El dinamismo más tenue de Bizkaia se explica por su comportamiento demográfico regresivo durante los últimos años y porque parte de su desarrollo inmobiliario se ha irradiado hacia territorios cercanos, tanto a Álava como a Cantabria o a La Rioja (Burriel, 2008). 
Cuadro 4

INCREMENTO PORCENTUAL DEL NÚMERO DE VIVIENDAS 1991-2011 (\%)

\begin{tabular}{|l|c|c|c|c|}
\hline & Total viviendas familiares & Unifamiliares & Bloque 3-10 viv. & Bloque >11 viv. \\
\hline Álava/Araba & 47,9 & 42,2 & 40,1 & 52,5 \\
Bizkaia & 25,0 & 23,1 & 17,3 & 28,6 \\
Gipuzkoa & 36,3 & 28,3 & 26,0 & 45,1 \\
\hline País Vasco & 31,7 & 28,9 & 23,1 & 36,5 \\
\hline España & 46,5 & 22,9 & \multicolumn{2}{|c|}{64,0} \\
\hline
\end{tabular}

Fuente: Eustat e INE. Elaboración propia.

El crecimiento inmobiliario de Álava también destaca por la importante entidad de las nuevas viviendas unifamiliares. Se trata de la provincia con mayor disponibilidad de suelo para acometer desarrollos urbanos y donde predominan los asentamientos pequeños de carácter netamente rural, que han canalizado estas modalidades en baja densidad, sin olvidar que el aumento de las plurifamiliares también ha sido importante en la capital y en cabeceras de cierta dimensión. Gipuzkoa se ha orientado hacia los desarrollos en altura, dada la menor disponibilidad de suelo y propiciados por un sistema urbano mejor estructurado conformado por una red de ciudades medias.

La Figura 2 saca a la luz las pautas territoriales del desarrollo residencial vasco desde una perspectiva espacial de mayor detalle. Los municipios con un crecimiento inmobiliario intenso durante las dos últimas décadas, en los cuales el aumento del número de viviendas ha superado la cifra del 50\%, se localizan en Álava central, tanto en la capital Vitoria-Gasteiz como en los municipios que la circundan, prolongándose al este de la comarca de Llanada Alavesa y al suroeste a lo largo de la carretera N-1. En Bizkaia radican en los municipios al norte de los de vieja industrialización del eje del Nervión: en el corredor del Txorierri y en la comarca de Plentzia-Mungia, entornos que conocieron prematuramente las presiones urbanas provenientes del Gran Bilbao (Urkidi, 2012). En Gipuzkoa los espacios con dinamismo inmobiliario intenso se sitúan en la orla que rodea Donostia/San Sebastián, proyectándose al oeste por el margen costero y su franja aledaña interior, así como al suroeste por la carretera N-1.

En términos generales los municipios con mayor crecimiento se localizan a la sombra de los entornos urbanos y metropolitanos tradicionales, en sus márgenes bien comunicados. Destacan puntualmente otros municipios más periféricos emplazados en espacios de marcado carácter rural de comarcas como Gernika-Bermeo, Arratia-Nervión o Tolosaldea, donde el desarrollo inmobiliario responde al renovado atractivo residencial que para clases de cierto estatus ejercen los espacios de elevado valor natural (Prados, 2006; Delgado, 2008, Torres, 2015). Por el contrario, los entornos urbanizados y congestionados con dificultades para expandirse (Margen Izquierda del Gran Bilbao), así como espacios rurales mal comunicados (Montaña Alavesa) muestran escaso dinamismo.

Los focos de actividad inmobiliaria no han correspondido a los espacios urbanos de mayor centralidad como fue habitual durante el periodo de intensa industrialización, puesto que el dinamismo se ha traslado a bandas colindantes con esos nodos y corredores tradicionales (Figura 3). Se han primado espacios con condiciones de accesibilidad media-alta 


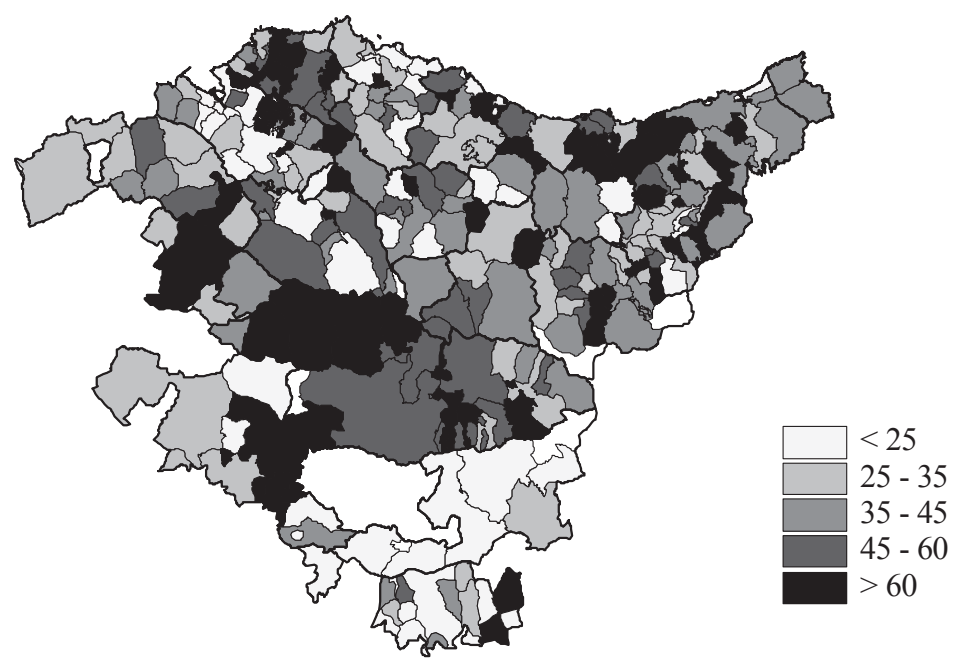

Fuente: Eustat. Elaboración propia.

Figura 3

INCREMENTO DE VIVIENDAS 1991-2011 (\%), EN FUNCIÓN DE LAS CONDICIONES DE ACCESIBILIDAD (IZDA.) Y DEL TIEMPO DE DESPLAZAMIENTO A LA CAPITAL (DCHA.)

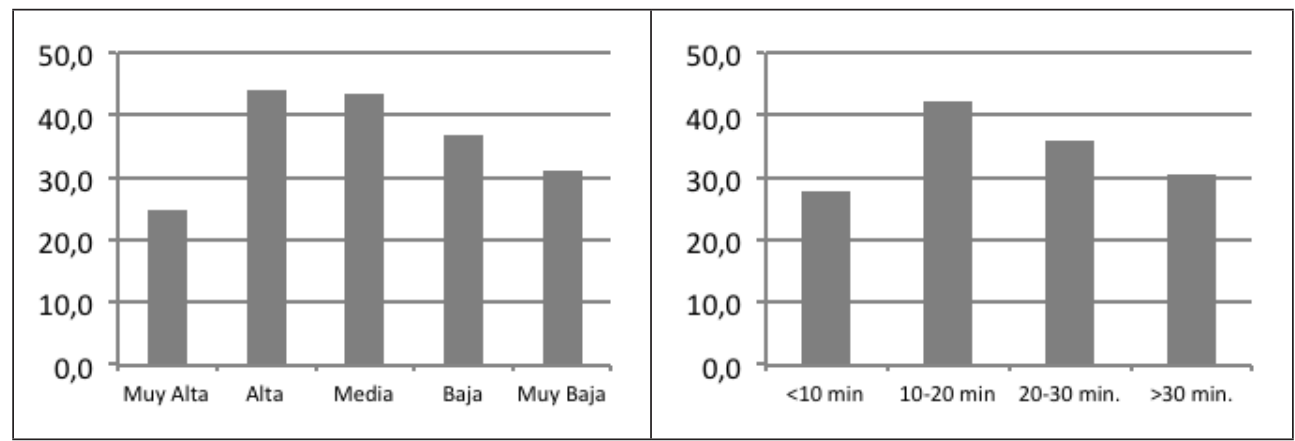

Fuente: Eustat, Udalmap. Elaboración propia.

emplazados entre las isócronas de 10-20 minutos que circundan a las capitales vascas, delatando que el significado estratégico de la centralidad ha sido reemplazado por el de la accesibilidad (Oliva y Rivera, 2003). El incremento porcentual del parque residencial, soslayando ligeros altibajos, ha alcanzado una envergadura inversamente proporcional al tamaño del asentamiento (Cuadro 5). Esto ha acarreado importantes transformaciones urbanísticas en los municipios menores de 5.000 habitantes, donde el número de viviendas ha aumentado por 
encima del $45 \%$ en dos décadas. Muchos de ellos han sufrido una drástica transformación de su idiosincrasia rural anterior, al quedar envueltos por orlas de nuevas viviendas unifamiliares o desfigurados por la introducción de vivienda colectiva que han alterado completamente las estructuras y morfologías urbanas de partida. Resultan especialmente relevantes los casos de Alegría-Dulantzi, Elburgo, Urduliz, Gatika, Fruiz, Asteasu, Olaberria, etc.

Cuadro 5

INCREMENTO PORCENTUAL DEL NÚMERO DE VIVIENDAS 1991-2011

EN MUNICIPIOS CLASIFICADOS POR DIMENSIÓN DEMOGRÁFICA

\begin{tabular}{|l|c|ccc|}
\hline & $\begin{array}{c}\text { Total viviendas } \\
\text { familiares }\end{array}$ & Unifamiliares & Bloque 3-10 viv. & Bloque > 11 viv. \\
\hline$<2.500$ hab. & 45,6 & 38,4 & 48,9 & 71,9 \\
$2.501-5.000$ & 48,0 & 27,6 & 43,4 & 66,3 \\
$5.001-10.000$ & 39,1 & 26,1 & 33,7 & 49,4 \\
$10.001-20.000$ & 33,3 & 14,6 & 24,7 & 44,6 \\
$20.001-40.000$ & 27,3 & 14,3 & 15,8 & 34,4 \\
$40.001-100.000$ & 21,9 & 28,1 & 14,2 & 25,4 \\
$>100.000$ & 29,5 & 22,8 & 12,9 & 34,2 \\
\hline
\end{tabular}

Fuente: Eustat. Elaboración propia.

Entre 1991 y 2011 tuvo lugar no solo un importante auge inmobiliario, sino también un cambio sustancial en los patrones espaciales, al haberse propagado espacialmente la actividad edificatoria hacia espacios de menor centralidad. Este proceso no ha sido fortuito, sino que ha estado respaldado en buena medida por los mecanismos establecidos en las Directrices de Ordenación Territorial del País Vasco aprobadas en 1997 y aún vigentes, si bien actualizadas y readecuadas a las nuevas circunstancias a través de la Modificación de las Directrices de Ordenación Territorial (2012). Las estrategias de corrección de los desequilibrios territoriales (Figura 4), buscaban una distribución más uniforme y menos polarizada de la población y las actividades por el territorio; para ello se propusieron acciones de reequilibrio del sistema urbano, actuando activamente en el reforzamiento de ciertos asentamientos secundarios mediante crecimientos selectivos y hábitats alternativos. La primera acción se destinaba a núcleos con cierta consistencia urbana hacia los que redirigir la oferta residencial que las áreas urbanas más congestionadas tenían dificultades para acoger, mientras que los segundos se propusieron como núcleos de bajas densidades y mayor contacto con la naturaleza llamados a potenciar modalidades residenciales menos estandarizadas.

Los Planes Territoriales Parciales de desarrollo de las Directrices de Ordenación actuaron en consecuencia, derivando parte del crecimiento residencial hacia estos municipios menores localizados en los márgenes bien comunicados de las áreas urbanas. El gran desarrollo de los municipios alaveses que circundan la capital, así como el que ha conocido el corredor del Txorierri o la comarca de Plentzia-Mungia ha respondido a estas estrategias: el planeamiento de municipios como Alegría-Dulantzi, Derio o Mungia ha contemplado grandes reclasificaciones de suelo para asumir estas estrategias de desconcentración. Estos desa- 
rrollos se han dimensionado mediante el modelo de cálculo implementado por las Directrices de Ordenación Territorial de 1997 con objeto de establecer las necesidades de vivienda que el planeamiento municipal de cada municipio debía contemplar durante su horizonte de vigencia. La oferta potencial de viviendas se fijaba a través de una fórmula matemática que consideraba diferentes componentes: las implicaciones del modelo territorial en el municipio en cuestión, es decir, las estrategias o acciones específicas contempladas por las Directrices, la previsión del crecimiento demográfico y de la variación del tamaño familiar, la segunda residencia y un factor de corrección de la rigidez de la oferta.

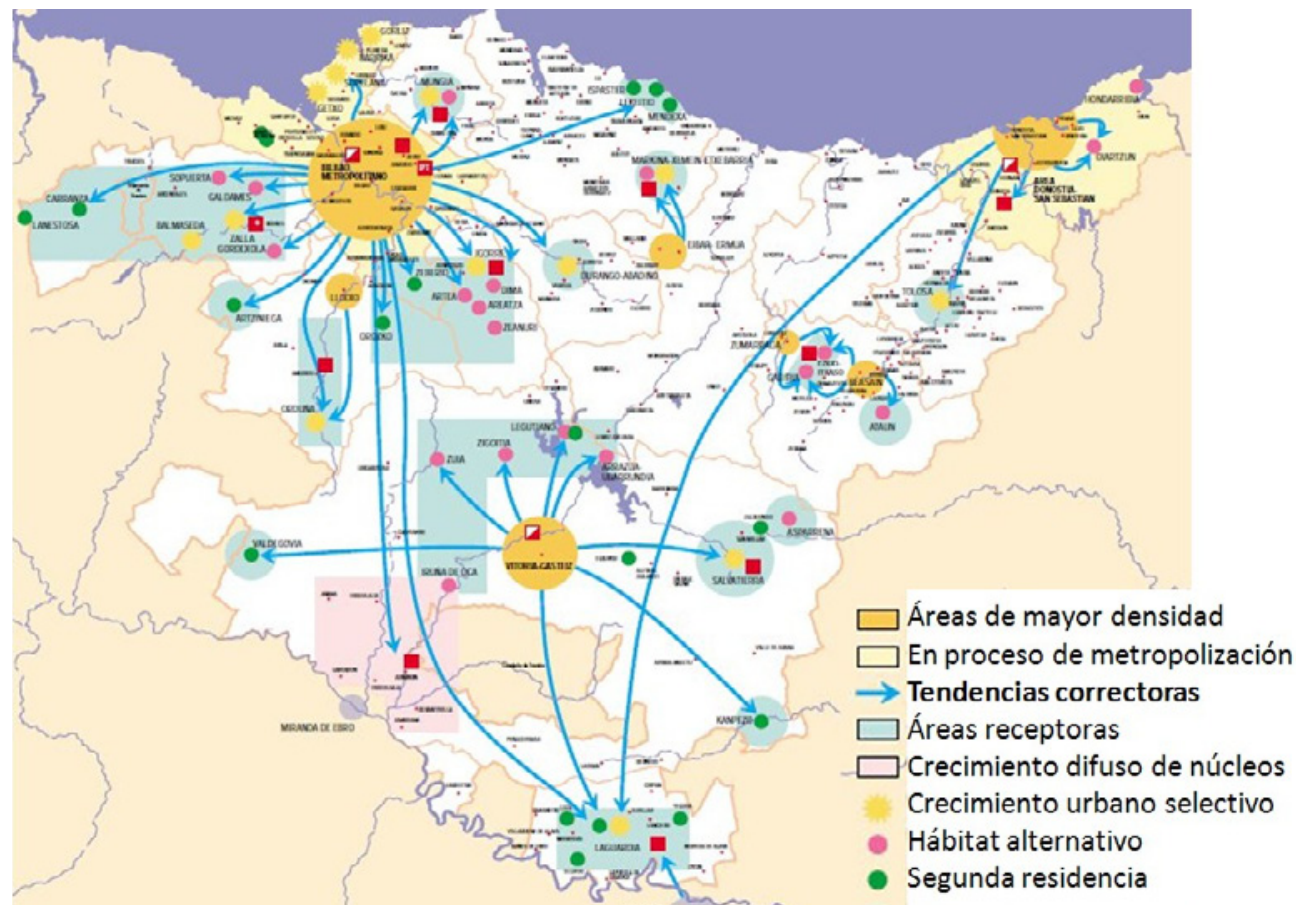

Fuente: Directrices de Ordenación Territorial de la CAPV, 1997. Adaptado.

En municipios afectados por estrategias de crecimientos selectivos o propuestos como hábitats alternativos recaía un mayor dimensionamiento de la oferta potencial de vivienda, de igual modo que aquellos otros en los que se propició la segunda residencia. También en el País Vasco las proyecciones demográficas para estimar las necesidades de suelo futuras han sido elaboradas en ocasiones con poco rigor, sobredimensionando las expectativas de crecimiento con el fin de justificar una oferta de vivienda elevada (Vinuesa y Martín, 2013). La aplicación de un factor de corrección de la oferta residencial, que buscaba dotar de suficiente suelo y evitar las fricciones de una oferta estrangulada por la demanda, ha afectado especialmente a municipios pequeños. En ellos se aplicaron coeficientes de holgura mayores 
para elevar el umbral de oferta máxima de vivienda, buscando prevenir situaciones indeseables como la competencia entre habitantes locales y los provenientes del exterior. Esta metodología de cuantificación ha pecado de una visión muy desarrollista, legitimando desde los propios Planes Territoriales Parciales propuestas de nuevas superficies residenciales desmesuradas (Ainz et al., 2008). Estas situaciones son palpables en la actualidad en comarcas como Encartaciones, Mungialdea o Valles Alaveses, donde abundan amplios sectores de suelo urbanizable sin desarrollar o escasamente consolidados.

Los ayuntamientos se han amparado en estos umbrales máximos de oferta de vivienda y los han sabido aprovechar para aumentar y diversificar la oferta residencial, tratando de ampliar el espectro social de nuevos residentes o retener a los jóvenes autóctonos. Han actuado con la mira puesta en los beneficios económicos que para las arcas municipales acarrean el aumento de los umbrales demográficos y el propio proceso de urbanización (Sánchez y Suárez, 2008; Fernández y Cruz, 2011). Con la reversión del contexto socio-económico y tras comprobarse la sobreoferta de suelo que el modelo de cálculo primitivo ha generado, la Modificación de las Directrices de 2012 ha reajustado la metodología de cálculo de la oferta de vivienda, resultando dimensionamientos más moderados, adaptados al escenario actual y a necesidades reales.

Durante los años expansivos del sector inmobiliario, las fuerzas de mercado supieron aprovecharse de las holgadas posibilidades ofrecidas por el marco normativo, de manera que el crecimiento urbanístico se intensificó propagándose hacia entornos alternativos a los tradicionales. Como resultado, el parque residencial vasco ha aumentado pero también ha mostrado una reconfiguración espacial (Cuadro 6). Los municipios de menor dimensión han ganado importancia en cuanto al peso relativo de las viviendas que alojan, en detrimento de los mayores de 20.000 habitantes, que en conjunto han perdido 2,1 punto porcentuales. Las mismas pautas se repiten en función de las condiciones de accesibilidad y centralidad de los municipios, de manera que mientras el peso residencial de los centros y ejes urbanos de primer orden se aminora, las orlas y márgenes bien conectados localizados bajo su sombra inmediata han cobrado relevancia: Uribe Costa y el corredor del Txorierri en Bizkaia, los municipios que circundan Vitoria-Gasteiz y los que bordean Donostia-San Sebastián, especialmente los emplazados en la franja litoral.

Cuadro 6

VARIACIÓN DEL PESO PORCENTUAL DEL PARQUE RESIDENCIAL ENTRE 1991 Y 2011, POR ÁMBITOS ESPACIALES

\begin{tabular}{|lccc|lccc|lccc|}
\hline \multicolumn{3}{|c|}{ En función de la dimensión demográfica } & \multicolumn{3}{|c|}{ En función de la accesibilidad } & \multicolumn{3}{c|}{ En función de la distancia a capital } \\
\hline & 1991 & 2011 & Variación & & 1991 & 2011 & Variación & & 1991 & 2011 & Variación \\
\hline$<2.500$ hab. & 7,5 & 8,3 & $\mathbf{0 , 8}$ & Muy Alta & 58,8 & 55,7 & $\mathbf{- 3 , 1}$ & $<10$ min & 61,2 & 59,4 & $\mathbf{- 1 , 8}$ \\
$2.501-5.000$ & 5,0 & 5,7 & $\mathbf{0 , 6}$ & Alta & 12,1 & 13,2 & $\mathbf{1 , 1}$ & $10-20$ min & 18,7 & 20,2 & $\mathbf{1 , 5}$ \\
$5.001-10.000$ & 8,4 & 8,9 & $\mathbf{0 , 5}$ & Media & 18,0 & 19,6 & $\mathbf{1 , 6}$ & $20-30$ min. & 10,7 & 11,0 & $\mathbf{0 , 3}$ \\
$10.001-20.000$ & 14,3 & 14,5 & $\mathbf{0 , 2}$ & Baja & 9,2 & 9,6 & $\mathbf{0 , 4}$ & $>30$ min. & 9,4 & 9,3 & $\mathbf{- 0 , 1}$ \\
$20.001-40.000$ & 9,5 & 9,2 & $\mathbf{- 0 , 3}$ & Muy Baja & 1,8 & 1,8 & $\mathbf{0 , 0}$ & & & & \\
$40.001-100.000$ & 14,6 & 13,5 & $\mathbf{- 1 , 1}$ & & & & & & & & \\
$>100.001$ & 40,6 & 39,9 & $\mathbf{- 0 , 7}$ & & & & & & & \\
\hline
\end{tabular}

Fuente: Eustat, Udalmap. Elaboración propia. 
La desconcentración demográfica y residencial ocurrida en los últimos años es consustancial al fortalecimiento de la dispersión urbana en el País Vasco. Como señala Nel·lo (2004), las dinámicas demográficas y urbanas de las décadas de 1960 y 1970 se explicaban por migraciones interregionales vinculadas al mercado de trabajo y beneficiaban a polos urbanoindustriales, pero a partir de 1980 pasan a estar determinadas por migraciones intrametropolitanas asociadas al mercado de la vivienda. Las nuevas pautas de propagación espacial del parque residencial vasco hacia entornos alternativos explican el sentido reciente de las migraciones internas. Al mismo tiempo, estos nuevos patrones espaciales de la vivienda han venido acompañados de transformaciones tipológicas y de uso que seguidamente se analizan.

\section{IV.2. Transformaciones tipológicas en el parque residencial vasco}

El parque residencial vasco, que ya era claramente plurifamiliar, ha virado hacia tipologías de mayor densidad, ya que el peso de la vivienda alojada en bloque de gran tamaño ha ganado 2,2 puntos porcentuales (Cuadro 7). Pero esta tendencia no ha sido la norma a lo largo de todo el periodo estudiado, puesto que se ha impuesto en la última década, entre 2001 y 2011, coincidiendo con el fuerte crecimiento inmobiliario. Durante la década anterior las pautas edificatorias se encaminaban en sentido contrario, aumentando ligeramente la relevancia de la vivienda unifamiliar y la de los bloques plurifamiliares de menor dimensión. Entre 1991 y 2001 el incremento del parque residencial alcanzó la cifra del 15,8\%, cuando predominó una demanda más vinculada al valor de uso propiciada por las generaciones que se emancipaban. La proliferación de la vivienda plurifamiliar en bloque de pequeño tamaño se explicaría atendiendo a la idiosincrasia de los entornos alternativos en los que fue cobrando fuerza el desarrollo inmobiliario, donde los nuevos desarrollos se plantearon bajo modalidades de menor volumen que encajaban mejor en el contexto originario. El aumento de vivienda unifamiliar fue acorde con la creciente demanda social, cuando muchas familias buscaban modalidades residenciales alternativas a las urbanas.

El cambio de tendencia hacia patrones edificatorios de mayor intensidad constatado en la década siguiente es consustancial al fuerte despegue del sector inmobiliario entre 2001 y 2011, periodo en que las viviendas crecieron un 27,8\%. Los emplazamientos favorecidos siguieron siendo municipios menores y más periféricos, pero se materializó a través de bloques de mayor volumen. El dinamismo inmobiliario y la construcción de edificios plurifamiliares de menor dimensión que tuvo lugar durante la década precedente, actuó como avanzadilla para la entrada posterior de tipologías más intensivas y netamente urbanas (Sopuerta, Fruiz, Lemoa, Getaria, Usurbil, Astigarraga). Otra causa de este fenómeno hay que buscarla en la Ley Vasca de Vivienda, que se ha centrado en la promoción de viviendas de protección oficial buscando satisfacer las necesidades de acceso de diferentes colectivos sociales. La cuota de mercado de la vivienda protegida durante el primer quinquenio del siglo se situó, con un 30,6\% a la cabeza del estado (Burón, 2005) y posteriormente a partir de 2007 ganó mucho peso relativo en detrimento de las libres, más perjudicadas por la crisis inmobiliaria (Altuzarra, 2012). La práctica totalidad de la vivienda protegida se materializa mediante bloques colectivos y estas promociones han ido cobrando fuerza en municipios alternativos a los netamente urbanos, circunstancia que también ha contribuido al protagonismo de las tipologías de mayor intensidad. 
Cuadro 7

VARIACIÓN EN LA COMPOSICIÓN DE LAS TIPOLOGÍAS DEL PARQUE RESIDENCIAL (PUNTOS PORCENTUALES)

\begin{tabular}{|l|c|c|c|c|c|c|c|c|c|}
\hline & \multicolumn{2}{|c|}{$1^{\text {a }}$ década $(1991-2001)$} & \multicolumn{2}{c|}{$2^{\text {a década }(2001-2011)}$} & \multicolumn{3}{c|}{ Periodo 1991-2011 } \\
\cline { 2 - 10 } & $\begin{array}{c}\text { Unifami- } \\
\text { liares }\end{array}$ & $\begin{array}{c}\text { Bloque } \\
3-10 \\
\text { viv. }\end{array}$ & $\begin{array}{c}\text { Bloque } \\
>11 \\
\text { viv. }\end{array}$ & $\begin{array}{c}\text { Unifami- } \\
\text { liares }\end{array}$ & $\begin{array}{c}\text { Bloque } \\
3-10 \\
\text { viv. }\end{array}$ & $\begin{array}{c}\text { Bloque } \\
>11 \\
\text { viv. }\end{array}$ & $\begin{array}{c}\text { Unifami- } \\
\text { liares }\end{array}$ & $\begin{array}{c}\text { Bloque } \\
3-10 \\
\text { viv. }\end{array}$ & $\begin{array}{c}\text { Bloque } \\
>11 \\
\text { viv. }\end{array}$ \\
\hline Álava/Araba & 0,2 & 0,2 & $-0,4$ & $-0,9$ & $-1,3$ & 2,2 & $-0,7$ & $-1,2$ & 1,9 \\
Bizkaia & 0,2 & 0,9 & $-1,0$ & $-0,3$ & $-2,5$ & 2,8 & $-0,1$ & $-1,7$ & 1,8 \\
Gipuzkoa & 1,6 & 0,8 & $-2,4$ & $-2,2$ & $-3,6$ & 5,9 & $-0,6$ & $-2,8$ & 3,4 \\
\hline País Vasco & 0,7 & 0,9 & $-1,6$ & $-0,9$ & $-2,9$ & 3,8 & $-0,2$ & $-1,9$ & 2,2 \\
\hline
\end{tabular}

Fuente: Eustat. Elaboración propia.

El incremento de bloques plurifamiliares ha afectado sobre todo a los municipios de menos de 5.000 habitantes (Figura 5). Tanto a los beneficiados por buenas condiciones de accesibilidad, hacia los que se ha desbordado la actividad inmobiliaria desde los centros más saturados, como a municipios excéntricos de peor accesibilidad que han conocido un aumento de la verticalidad del parque residencial. Cabe matizar que en estos emplazamientos siguen dominando unas formas residenciales más laxas que en los municipios urbanos, si bien las transformaciones sufridas durante los últimos años han alterado el aspecto originario de algunos núcleos. Destaca a modo de ejemplo la nueva fisionomía urbana de pequeñas cabeceras como Fruiz, Gatika, Ajangiz u Orendain, donde han aparecido bloques de pequeña altura (2 ó 3 plantas), que se integran con mayor o menor acierto en el tejido urbano originario y se han materializado mediante diseños arquitectónicos más tradicionales en unos casos y más vanguardistas en otros. En cualquier caso, han alterado de forma irreversible su fisionomía rural tradicional predominante hasta hace pocos años. (IZDA.) Y DE LAS CONDICIONES DEACCESIBILIDAD (DCHA.), 1991-2011 (PUNTOS PORCENTUALES).

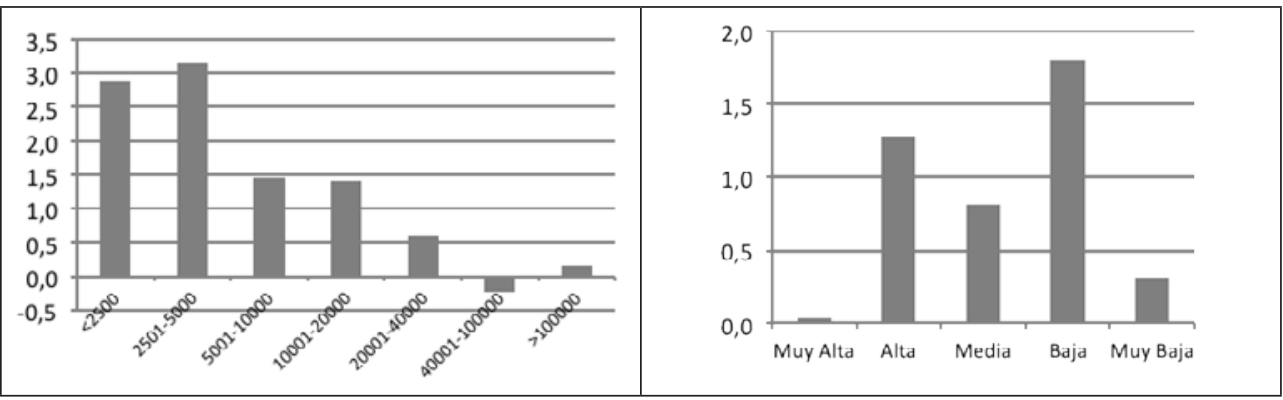

Fuente: Eustat, Udalmap. Elaboración propia.

A través de una óptica de análisis espacial más fina sale a la luz la relevancia alcanzada por las modalidades plurifamiliares en pequeños municipios (Figura 6). En áreas bajo influencia urbana como son el Txorierri al norte de Bilbao o algunos municipios cercanos a 
Donostia/San Sebastián el aumento de la vivienda colectiva ha sido significativo, pero los valores relativos alcanzan cotas superiores en municipios excéntricos de Arratia-Nervión, Markina-Ondarroa o Tolosaldea. La incidencia de desarrollos verticales ha destacado en los municipios interiores y menos accesibles de las comarcas de Plentzia-Mungia y UrolaCosta, que se mantuvieron en la retaguardia de los pioneros del borde costero. Al propagarse con posterioridad el dinamismo constructivo hacia el interior, afectó a los municipios que se habían mantenido al margen durante la primera oleada, pero entonces el fenómeno alcanzó mayor envergadura y se materializó bajo tipologías más intensivas. La promoción de viviendas colectivas a menudo ha respondido al deseo de ayuntamientos pequeños por ampliar el abanico de nuevos residentes o evitar la salida de jóvenes locales. De este modo se edificaban viviendas convencionales más asequibles, una parte de las cuales eran de protección pública.

Sin embargo, a pesar de la tendencia a la verticalidad generalizada, un reconocimiento más atento de la Figura 6 deja al descubierto el comportamiento diferente de algunos municipios densamente urbanizados. Dos de las capitales vascas, Donostia/San Sebastián y VitoriaGasteiz han visto disminuir, si bien muy ligeramente, el peso de la vivienda colectiva, lo que indica una proliferación de viviendas unifamiliares en los últimos años. Lo mismo ocurre en varios municipios urbanos de la órbita de la capital guipuzcoana (Irún, Lasarte-Oria, Zarautz), así como en el eje costero situado al norte de la capital vizcaína entre Getxo y Gorliz, que goza de ventajosas condiciones de accesibilidad con el centro del espacio metropolitano gracias a una red viaria renovada y al metro.

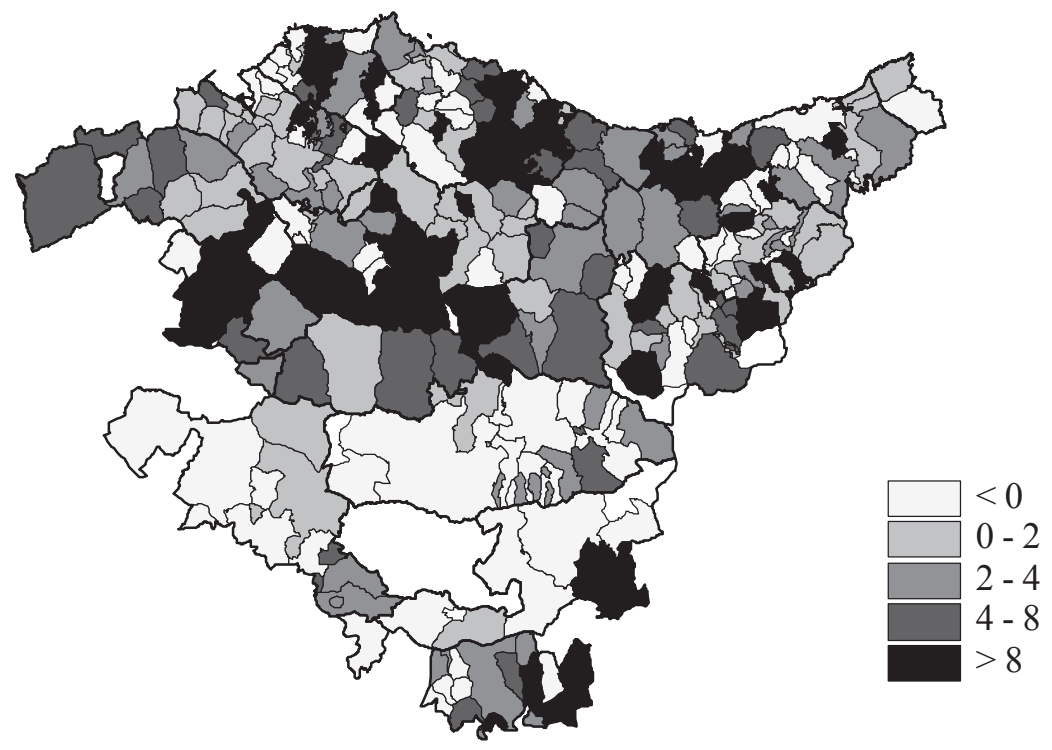

Fuente: Eustat. Elaboración propia. 
Se confirma lo que el Cuadro 5 ya dejaba entrever: si bien la edificación de vivienda unifamiliar se ha orientado hacia los ámbitos que le son más propicios, es decir, los municipios de menor dimensión demográfica, la tasa de incremento de unifamiliares repunta a partir del umbral de los 40.000 habitantes. Precisamente es en este grupo que incluye a varios municipios citados arriba, donde el peso de la colectiva ha descendido tenuemente (Figura 5). La demanda social por entornos de baja densidad fue recogida en los planes urbanísticos de ciudades caracterizadas por altas densidades, de forma que en municipios vascos también se calificaron buen número de sectores destinados a modalidades unifamiliares que han originado nuevas periferias residenciales extensivas que recuerdan a modelos anglosajones. En áreas de borde de las ciudades vascas han proliferado polígonos residenciales conformados por vivienda unifamiliar seriada que repiten patrones arquitectónicos estandarizados: periferia de Vitoria-Gasteiz, Getxo, Berango, Sondika, Lasarte-Oria, Urnieta, etc.

El resultado son nuevos paisajes periurbanos homogéneos, uniformes y despersonalizados como los generalizados también en otros espacios metropolitanos españoles (García y Gutiérrez, 2007; Muñoz, 2008; Coq, 2012), que bien podrían encuadrarse en el fenómeno de la urbanalización (Muñoz, 2008). En todo caso, estos crecimientos en extensión materializados a la sombra de los centros urbanos vascos no resultan acordes con los principios generales de la Ley de Suelo y Urbanismo del País Vasco de 2006, que reclama una política más intensiva en detrimento de los modelos esponjados de baja densidad, por lo que este tipo de actuaciones deberán ser reformuladas en el futuro. En la situación opuesta, la densificación de asentamientos menores por la edificación de bloques, pese a implicar un uso más efectivo del suelo, incide negativamente en la idiosincrasia del núcleo primitivo y puede trastocar la jerarquía de asentamientos, lo que requerirá vigilar la adecuada integración tipológica y estructural de las nuevas urbanizaciones tal y como insisten los Planes Territoriales.

De esta forma, el desarrollo urbano en baja densidad ha tenido especial relevancia en entornos situados a la sombra de grandes centros urbanos, si bien ha quedado parcialmente eclipsado por la tendencia general del periodo, marcada por el aumento de protagonismo de la vivienda plurifamiliar especialmente en municipios menores de 5.000 habitantes. El crecimiento en extensión que ha tenido lugar en las ciudades y sus periferias inmediatas, contrasta con el incremento de la verticalidad que simultáneamente ha estado ocurriendo en municipios menores y más alejados. En el País Vasco entre 1991 y 2011 ha tenido lugar una suerte de convergencia entre distintas tipologías edificatorias, al difundirse y propagarse tanto las unifamiliares como las plurifamiliares hacia los entornos que previamente no les eran característicos. De esta manera la dispersión urbana vasca se ha materializado bajo un modelo más parecido al de la Europa mediterránea, no solo asociada a la vivienda unifamiliar sino también a viviendas colectivas (García y Gutiérrez, 2007). A pesar de los bloques, en los desarrollos urbanos recientes predominan entramados menos compactos que los de décadas pasadas, al tiempo que las morfologías tienden a reproducir el «estilo universal» generalizado por todo el país durante los años de fuerte crecimiento (Naredo y Frías, 2007).

\section{IV.3. Cambios en la intensidad de ocupación del parque residencial}

El parque residencial vasco ha evolucionado desde 1991 hacia un uso más efectivo, ya que el peso de la vivienda principal ha aumentado 3,2 puntos porcentuales. La tendencia se 
repite en los tres territorios, aunque con una intensidad desigual, ya que es en Álava donde mayor entidad alcanza a costa de la reducción del peso de las secundarias y las vacías. Pero una vez más, el comportamiento general del periodo esconde dinámicas contrapuestas, ya que la tendencia hacia el uso más intenso de las viviendas se impuso con fuerza entre 1991 y 2001, pero en la década siguiente revierte como consecuencia del incremento de la vivienda desocupada. En 2001-2011 el peso de la vivienda vacía sube 1,2 puntos en el País Vasco y destaca en Álava (Cuadro 8).

Cuadro 8

VARIACIÓN EN LA INTENSIDAD DE USO DEL PARQUE RESIDENCIAL (PUNTOS PORCENTUALES)

\begin{tabular}{|l|c|c|c|c|c|c|c|c|c|}
\hline & \multicolumn{3}{|c|}{$1^{\text {a década }(1991-2001)}$} & \multicolumn{2}{c|}{$2^{\text {a década (2001-2011) }}$} & \multicolumn{3}{c|}{ Periodo 1991-2011 } \\
\cline { 2 - 10 } & Principales & Secundarias & Desocupadas & Principales & Secundarias & Desocupadas & Principales & Secundarias & Desocupadas \\
\hline Álava/Araba & 6,4 & $-1,3$ & $-5,0$ & $-0,5$ & $-2,6$ & 3,1 & 5,9 & $-3,9$ & $-1,9$ \\
Bizkaia & 3,9 & $-0,5$ & $-3,4$ & $-0,4$ & $-0,2$ & 0,6 & 3,5 & $-0,7$ & $-2,8$ \\
Gipuzkoa & 2,7 & 0,1 & $-2,8$ & $-1,1$ & $-0,3$ & 1,4 & 1,6 & $-0,2$ & $-1,4$ \\
\hline País Vasco & 3,8 & $-0,4$ & $-3,4$ & $-0,7$ & $-0,6$ & 1,2 & 3,2 & $-1,0$ & $-2,2$ \\
\hline
\end{tabular}

Fuente: Eustat. Elaboración propia.

A pesar del tenue dinamismo demográfico entre 1991 y 2001, la emancipación de generaciones extensas, la disminución del tamaño medio familiar y la generalización de hogares unipersonales, ocasionó un aumento en la intensidad de ocupación de las viviendas. Pero a partir de 2001, coincidiendo con la aceleración inmobiliaria, cobra fuerza la vivienda desocupada, que en el País Vasco se mantiene retenida alegando su reserva para los hijos y la generación rentas (Urrutia, 2006; Altuzarra, 2012). Muchas viviendas se adquirían como bien de inversión por la fuerte revalorización anual del precio, convirtiéndose en refugio del ahorro familiar. Otra parte de las viviendas vacías corresponde al stock que el mercado es incapaz de absorber por la caída de la demanda tras el pinchazo de la burbuja inmobiliaria, lo que es palpable en Álava, tanto en los municipios menores como en la propia capital.

A pesar de ese cambio de tendencia reciente, en términos globales entre 1991 y 2011 la participación de la vivienda principal aumentó de manera importante en los municipios localizados en los márgenes bien comunicados desde los centros y corredores urbanizados: alrededor de Vitoria-Gasteiz, en el eje litoral al norte de Bilbao, así como en el de la N-1 y en la costa de Gipuzkoa (Figura 7). A su favor han actuado de forma simultánea dos circunstancias: la mayor parte de las nuevas viviendas edificadas en estos entornos privilegiados se destinaban a residencia permanente, al tiempo que muchas viviendas infrautilizadas se transformaban en principales.

La ocupación permanente de viviendas estivales ha sido frecuente en los municipios litorales situados al norte de Bilbao, donde abundaban segundas residencias que sustentaron la reubicación de familias en una primera oleada colonizadora. Muchos traslados posteriormente se asentaron en la edificación de nueva vivienda, parte de la cual se difundió hacia una franja de municipios localizados más al interior, motivo por el cual la intensidad inmobiliaria registrada ha sido mayor en este segundo sector que en el frente litoral, fenómeno que tam- 
bién se percibía en la franja costera de Gipuzkoa (Figura 2). Así, la aparición de viviendas principales ha estado originada por la ocupación continuada de antiguas residencias estivales, a lo que luego se sumó la construcción de nuevas directamente ocupadas como principales.

Figura 7

VARIACIÓN DEL PESO DE LA VIVIENDA PRINCIPAL, 1991-2011(PUNTOS PORCENTUALES)

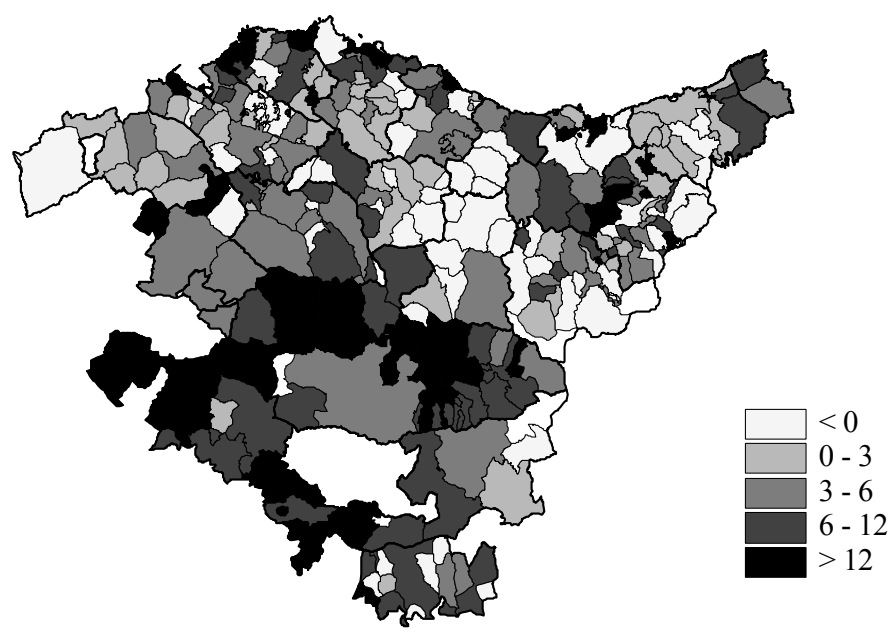

Fuente: Eustat. Elaboración propia.

Por el contrario, el peso de la vivienda principal disminuye en municipios rurales excéntricos de la vertiente atlántica pero también en los industriales del oeste de Gipuzkoa, tal y como refleja el insólito aumento de la vivienda secundaria registrado en municipios entre 10.001-40.000 habitantes (Cuadro 9). En muchos de Alto Deba y su entorno, pero también en Gran Bilbao o Duranguesado, al contrario de lo que la lógica haría suponer por tratarse de municipios netamente urbanos sin atractivos estivales o recreativos han crecido las viviendas secundarias, fenómeno que hay que vincular al dinamismo demográfico regresivo señalado atrás (Cuadro 3).

Muchas familias abandonaron núcleos urbanos congestionados buscando entornos residenciales alternativos mejor valorados, localizados en la costa o en municipios del interior que gozan de atractivos ambientales. De modo que la anterior residencia ha pasado a registrarse como secundaria, funcionando como alojamiento alternativo en la ciudad para los miembros de la familia que la ocupan de forma eventual durante estancias cortas vinculadas a motivos laborales o de estudios. Un fenómeno similar han detectado García y Gutiérrez (2007) en las diferentes coronas metropolitanas de la aglomeración madrileña. No pueden desestimarse motivaciones especulativas que animaron a la retención de la anterior vivienda o la dificultad para venderla después, como coadyuvantes del aumento de viviendas no principales en municipios de relativa centralidad. En todo caso, el cese en la ocupación continuada de esas viviendas comporta el aumento de las principales en los nuevos municipios receptores (Cuadro 9). 
Cuadro 9

VARIACIÓN EN LA INTENSIDAD DE OCUPACIÓN DEL PARQUE RESIDENCIAL EN FUNCIÓN DEL EMPLAZAMIENTO, 1991-2011 (PUNTOS PORCENTUALES DE DIFERENCIA)

\begin{tabular}{|l|ccc|c|ccc|}
\hline \multicolumn{4}{|c|}{$\begin{array}{c}\text { En municipios clasificados } \\
\text { por dimensión demográfica }\end{array}$} & \multicolumn{3}{c|}{$\begin{array}{c}\text { En municipios según tiempo } \\
\text { de desplazamiento a capital }\end{array}$} \\
\hline & Principales & $\begin{array}{c}\text { Secunda- } \\
\text { rias }\end{array}$ & $\begin{array}{c}\text { Desocu- } \\
\text { padas }\end{array}$ & & Principales & $\begin{array}{c}\text { Secunda- } \\
\text { rias }\end{array}$ & $\begin{array}{c}\text { Desocu- } \\
\text { padas }\end{array}$ \\
\hline$<2.500$ hab. & 7,9 & $-9,2$ & 1,3 & $<10 \mathrm{~min}$ & 3,0 & $-0,6$ & $-2,4$ \\
$2.501-5.000$ & 3,9 & $-4,0$ & 0,0 & $10-20 \mathrm{~min}$ & 5,6 & $-1,7$ & $-3,9$ \\
$5.001-10.000$ & 4,8 & $-1,3$ & $-3,5$ & $20-30 \mathrm{~min}$. & 3,1 & $-2,5$ & $-0,7$ \\
$10.001-20.000$ & 2,8 & 1,6 & $-4,4$ & $>30 \mathrm{~min}$. & 0,5 & $-1,1$ & 0,6 \\
$20.001-40.000$ & 1,0 & 0,6 & $-1,6$ & & & & \\
$40.001-100.000$ & 3,3 & $-0,2$ & $-3,1$ & & & & $-1,0$ \\
\cline { 5 - 8 } & 3,0 & $-0,9$ & $-2,2$ & País Vasco & 3,2 & \\
\hline
\end{tabular}

Fuente: Eustat, Udalmap. Elaboración propia.

La intensificación del uso del parque residencial ha beneficiado a municipios menos poblados y bien emplazados pero de menor centralidad, en consonancia con las dinámicas demográficas e inmobiliarias del periodo. La consolidación de saldos migratorios internos inversamente proporcionales al tamaño del municipio explica la creación de nuevos hogares en esos asentamientos menores. La previa existencia de viviendas secundarias canalizó parte de la colonización permanente en un primer momento, pero posteriormente bascula en la edificación de nuevas viviendas, al ser precisamente estos entornos los que se han beneficiado de las estrategias de reequilibrio territorial de las Directrices de Ordenación Territorial.

La vivienda desocupada, que aumenta entre 2001 y 2011, ha tendido a municipios más pequeños y periféricos, donde fue ganando fuerza la actividad inmobiliaria conforme se afianzaba la burbuja inmobiliaria. En municipios del Txorierri, Plentzia-Mungia, Donostialdea y Urola Costa, así como en buena parte de los alaveses y en otros más excéntricos de Gernika-Bermeo o Goierri, la presencia de vivienda vacía alcanza una dimensión superior a la media en la actualidad. Si bien es cierto que muchos de ellos estaban registrando un importante crecimiento demográfico y la oferta residencial parecía acorde con ello, hasta la reversión del ciclo económico no se hizo patente su excesivo dimensionamiento, ya que se encontraba desacoplado de las necesidades derivadas de factores estrictamente demográficos.

\section{UNA EVOLUCIÓN MARCADA POR LOS CICLOS ECONÓMICOS}

La dinámica inmobiliaria presenta una progresión condicionada por la burbuja inmobiliaria. Si bien las series estadísticas relativas a las licencias de edificación de vivienda nueva adolecen de la profundidad temporal de las anteriores, la Figura 8 refleja la evolución de los últimos años en los tres territorios vascos. El número de licencias fue aumentando con carácter general año a año hasta tocar techo en 2007, tras lo cual se desplomó cerca de un $40 \%$ y siguió cayendo posteriormente de forma más moderada con ligeros altibajos. De manera que el año 2013 registró menos de la cuarta parte de licencias que una década antes y tan solo un $16 \%$ respecto a las del máximo de 2007. 


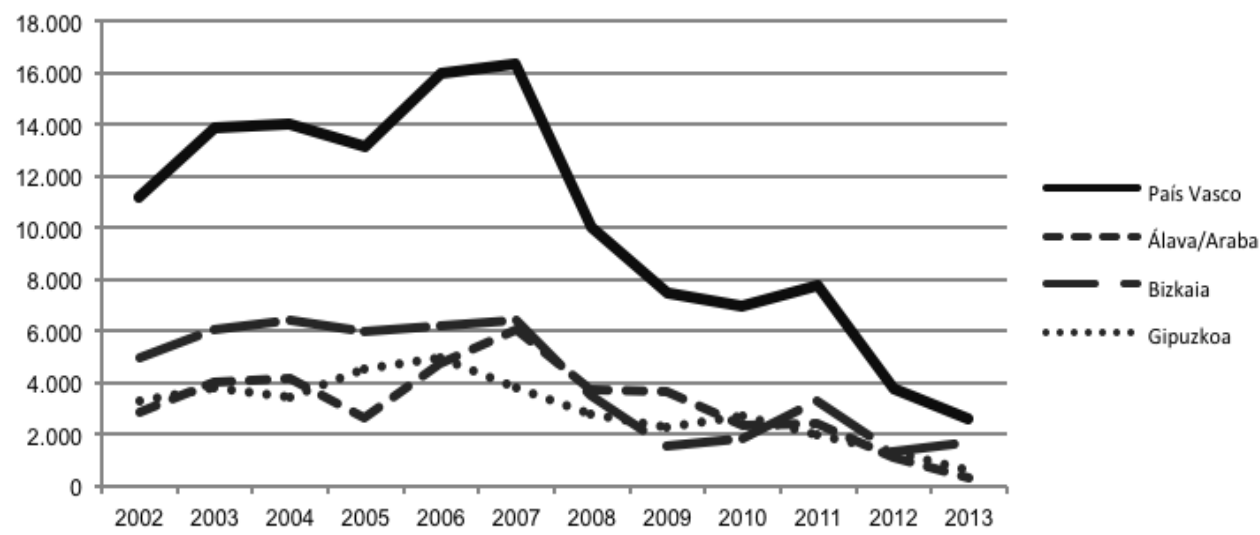

Fuente: Dpto. de Vivienda, Obras Públicas y Transportes del G.V. Elaboración propia.

La intensidad del dinamismo inmobiliario ha sido desigual en el País Vasco. El mayor número de licencias corresponde a Bizkaia, por acoger a la mitad de la población vasca, pero en términos relativos ha sido Álava la más desarrollista dada la desproporción entre el volumen de licencias concedidas y su bajo peso demográfico. La tasa media anual de cada Territorio Histórico durante ese periodo es elocuente de la desigualdad del sector inmobiliario: alcanzaba 10,3 licencias por mil habitantes en Álava, no llegaba a la mitad en Gipuzkoa con 4,2, mientras en Bizkaia era de 3,6.

En 2008 las tres provincias registran una drástica caída de las licencias, muy profunda en Bizkaia, pese a que posteriormente mostrará indicios de cierta recuperación. La alimentación de la burbuja durante los años precedentes a su explosión fue allí más moderada, ya que el aumento interanual previo era tenue, a diferencia de Álava, donde el despegue fue más tardío y acelerado pero cayó sin insinuar una recuperación. En Gipuzkoa la curva revelaba un ascenso suave y la desaceleración empezó antes, por lo que no se originó una caída tan brusca. El mayor impacto del reajuste se ha producido por tanto donde durante los años de crecimiento el proceso constructivo alcanzó mayor desproporción, tal y como también constatan Fernández y Cruz (2011).

A lo largo del periodo las dinámicas inmobiliarias fueron propagándose por todo el territorio vasco, alcanzando a municipios que habían permanecido al margen de las transformaciones urbanísticas de las áreas industriales de mayor centralidad. Progresivamente la construcción de viviendas fue cobrando fuerza en municipios de menor dimensión demográfica y situados en entornos de accesibilidad menos aventajada, logrando allí las tasas más elevadas en el quinquenio 2001-06 (Figura 9). Al tiempo de la desconcentración de la población, se fue materializando la dispersión espacial de las funciones urbano-residenciales por el territorio, lo que ha acarreado el aumento del peso residencial de los espacios alternativos constatado atrás (Cuadro 6). 


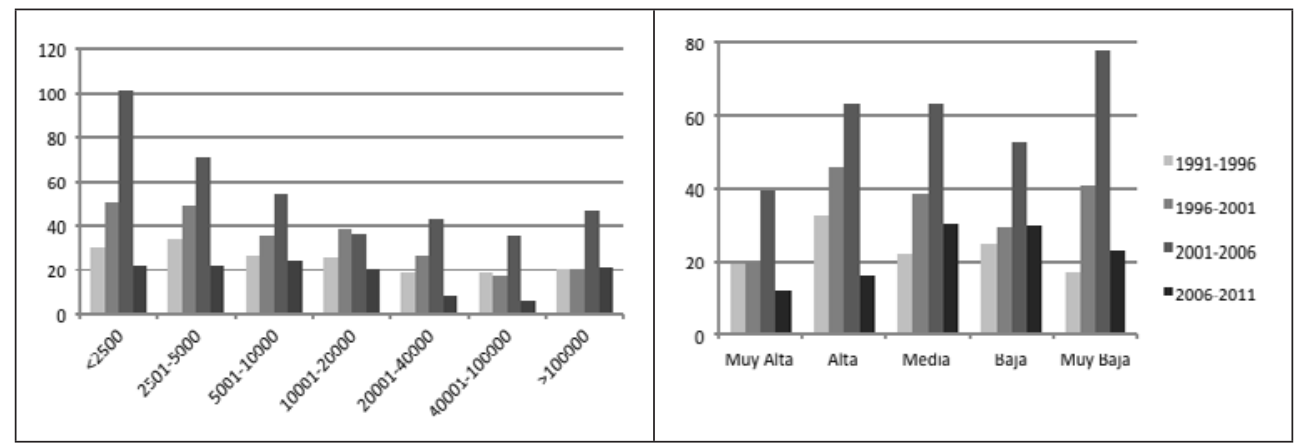

Fuente: Eustat. Udalmap. Elaboración propia.

Durante los años de fuerte crecimiento del sector inmobiliario se confabularon las fuerzas de mercado con las disposiciones favorables derivadas de las Directrices de Ordenación. La coyuntura expansionista de aquel momento se aprovechó de las posibilidades brindadas por los instrumentos de ordenación supramunicipal, con lo que se abrieron las puertas a la promoción de viviendas en asentamientos alternativos. Las tendencias correctoras propuestas a favor de un reequilibrio territorial orientaron la colonización de nuevos entornos y al mismo tiempo, la aplicación de la metodología de cálculo establecida para fijar las necesidades de vivienda se enfocó con demasiada frecuencia a explotar las posibilidades más provechosas para el interés urbanístico.

A las primeras Directrices se les achaca ser poco garantistas de hecho frente a los impactos provocados por la colonización de nuevos suelos, ya que algunas de sus propias estrategias han conducido a operaciones de baja densidad (Ruiz y Galdos, 2009). La cuantificación de las necesidades de vivienda de cada municipio requeriría haber sido complementada con otro tipo de normas y restricciones más vinculadas a la capacidad de acogida de cada territorio, para favorecer así crecimientos más compactos en los núcleos urbanos y evitar la propagación de la urbanización difusa hacia entornos más excéntricos. La ley de Suelo y Urbanismo vasca en vigor desde 2006, así como la Modificación de las Directrices de Ordenación Territorial de 2012, asumen que estas dinámicas urbanas generalizadas durante los últimos años son perniciosas e indeseables, pero deberán ir más allá de la mera declaración de intenciones si efectivamente quieren atajarlas y reconducirlas.

\section{CONCLUSIONES}

Entre 1991 y 2011 el aumento relativo del parque residencial vasco se situó muy por encima del tenue dinamismo demográfico. Los municipios de menor tamaño localizados en los márgenes de las áreas metropolitanas y de los principales corredores urbanos conocieron un importante incremento del número de viviendas, con lo que se manifiesta una reconfiguración en las pautas territoriales, al haberse visto favorecidos entornos residenciales alterna- 
tivos a los densos espacios urbanos tradicionales. La búsqueda de precios de la vivienda más asequibles, junto con la atracción ejercida por hábitats descongestionados bajo modalidades menos estandarizadas, explicarían la tendencia reciente, que en todo caso se ha materializado a través de las instrucciones de las Directrices de Ordenación Territorial del País Vasco de 1997, que en pos de un reequilibrio en la distribución de la población y en el sistema de asentamientos, fomentaron la oferta de vivienda en cabeceras urbanas de segundo y tercer rango.

Conforme avanza el periodo y se intensifica la actividad inmobiliaria, influida en parte por el impulso de la vivienda pública, fue cobrando fuerza la colonización residencial de asentamientos menores y más excéntricos que hasta entonces habían permanecido ajenos a esas dinámicas. No solo conocen un considerable aumento del número de viviendas, sino también un desarrollo vertical al difundirse nuevos bloques plurifamiliares, que han alterado la fisionomía originaria de muchos núcleos. De forma paralela, en localizaciones bien comunicadas bajo la sombra directa de las capitales ha proliferado la vivienda unifamiliar, de lo que han resultado sectores de baja densidad formados por adosados seriados y estandarizados. Se ha asistido a procesos aparentemente contradictorios, al simultanearse expansiones de bajas densidades en las periferias de los núcleos más densamente urbanizados, con desarrollos en altura de asentamientos de menor centralidad que partían de modalidades residenciales extensivas.

A pesar de que el parque residencial vasco ha ido orientándose hacia un uso más efectivo, a partir de 2001 se trastoca la tendencia debido al aumento de la vivienda desocupada. Las residencias secundarias han funcionado como pasarela para el traslado de hogares a espacios litorales y naturales accesibles donde previamente abundaban, de forma que al pasar a ser permanentemente ocupadas su representación disminuye en esos entornos periféricos pero aumenta ligeramente en algunos centros urbanos. La vivienda vacía se encuentra sobrerrepresentada en municipios que protagonizaron desarrollos urbanos destacados, lo que delata el excesivo dimensionamiento de la oferta de vivienda durante la segunda década del periodo estudiado, especialmente en entornos donde el despegue inmobiliario fue más tardío y rápido.

La evolución en la edificación de nuevas viviendas conoció tal aceleración que duplicó su intensidad en apenas una década, al tiempo que fue propagándose por todo el territorio alcanzando su mayor envergadura relativa en municipios pequeños de menor centralidad. Con ello se ha probado que la difusión de patrones propios de la dispersión urbana también ha tenido lugar en el País Vasco, cuyo reconocimiento en profundidad requerirá de un estudio específico. Aquella tendencia expansiva revertió súbitamente en 2007 con el pinchazo de la burbuja inmobiliaria y el cambio de ciclo económico, dejando al descubierto un conjunto de secuelas derivadas de la desmesurada actividad constructora y urbanizadora de los años precedentes que será necesario abordar.

\section{BIBLIOGRAFÍA}

AINZ, M.J., GONZÁLEZ, M.J. y MORO, I (2008): Sostenibilidad de las propuestas de suelo para nuevos desarrollos residenciales en la Planificación Territorial de Bizkaia. Fórum de la Sostenibilidad, Cátedra UNESCO de la UPV/EHU.

Disponible en http://www.ehu.es/cdsea/web/revista/numero_2/forum_sost_2_111-125.pdf 
ALTUZARRA ARTOLA, A. (2012): «Vivienda» en Informe socio-económico de la C.A. de Euskadi 2012. Vitoria-Gasteiz, Eustat, 543-582.

BLANCO LOSADA, M.A., FRUTOS, R., LÓPEZ, E. y MARTÍNEZ, J.S. (2013): «Auge y colapso de la demanda de viviendas en España. Factores determinantes». IAES, Universidad de Alcalá. Disponible en http://digital.csic.es/bitstream/ 10261/76384/1/Auge\%20 y\%20colapso\%20de\%20 la\%20demanda\%20de\%20viviendas.pdf

BORISSOVA BONEVA, M. (2007): «El traslado de la vivienda al medio rural: urbanizaciones y viviendas aisladas» en El medio rural y la difusión urbana (Fernández, A. y Alonso, M.R., Coords.) Oviedo, KRK Ediciones, 91-106.

BURÓN, J. (2005): «La política de vivienda del Gobierno Vasco». Documentación Social, $\mathrm{n}^{\mathrm{o}} 138,119-156$.

BURÓN J. (2008): «Una política de vivienda alternativa». Ciudad y Territorio: Estudios Territoriales, $\mathrm{n}^{\mathrm{0}} 155,9-40$.

BURRIEL DE ORUETA, E.L. (2008): «La 'década prodigiosa' del urbanismo español (1997-2006)». Scripta Nova, vol. XII, n 270. Disponible en http://www.ub.edu/geocrit/xcol/383.htm

CEBRIÁN ABELLÁN, F. (2007): «Transformaciones y ajustes ante las nuevas dinámicas urbanas. Manifestaciones en la organización del territorio de Castilla-La Mancha». Estudios Geográficos, vol. 68, n 262, 7-32.

COQ HUELVA, D. (2012): «Crecimiento suburbano difuso y sin fin en el área metropolitana de Sevilla entre 1980 y 2010. Algunos elementos explicativos». Scripta Nova, vol. XVI, no 397. Disponible en http://www.ub.edu/geocrit/sn/sn-397.htm

DELGADO VIÑAS, C. (2008): «Urbanización sin fronteras. El acoso urbanístico a los espacios naturales protegidos». Boletín de la Asociación de Geógrafos Españoles, n 47, 271-310.

DEPARTAMENTO DE ORDENACIÓN DEL TERRITORIO, VIVIENDA Y MEDIO AMBIENTE (1997): Directrices de Ordenación Territorial de la Comunidad Autónoma del País Vasco. Vitoria-Gasteiz, Gobierno Vasco.

DEPARTAMENTO DE MEDIO AMBIENTE, PLANIFICACIÓN TERRITORIAL, AGRICULTURA Y PESCA (2012): Modificación de las DOT como consecuencia de su Reestudio. Vitoria-Gasteiz, Gobierno Vasco.

FERNÁNDEZ GARCÍA, A. (2009): «Difusión urbana, ordenación del territorio y desarrollo sostenible». Ambienta, $\mathrm{n}^{\circ}$ 88, 20-27.

FERNÁNDEZ TABALES, A. y CRUZ MAZO, E. (2011): «Territorio y actividad constructora: del 'tsunami' a la crisis. Factores explicativos y propuesta de indicadores a escala municipal en Andalucía». Boletín de la Asociación de Geógrafos Españoles, $\mathrm{n}^{\circ}$ 56, 79-110.

FERRÁN ARANAZ, M. (2011): «La evolución del sector de la construcción residencial. Una descripción territorial». Ciudad y territorio: Estudios territoriales, $\mathrm{n}^{\circ}$ 168, 339-363.

FONT ARELLANO, A. (2007): «Morfologías metropolitanas contemporáneas de baja densidad» en La ciudad de baja densidad. Lógicas, gestión y contención (Indovina, F., coord.) Diputació de Barcelona, 97-108.

GAJA DÍAZ, F. (2008): «El 'tsunami urbanizador' en el litoral mediterráneo. El ciclo de hiperproducción inmobiliaria 1996-2006». Scripta Nova, vol. XII, n 270. Disponible en http://www.ub.edu/geocrit/sn/sn-270/sn-270-66.htm 
GALDOS URRUTIA, R. y RUIZ URRESTARAZU, E. (2008): «La urbanización de los espacios rurales en el País Vasco» en Los espacios rurales en el nuevo siglo (Gómez Espín, J.M. y Martínez Medina, R., Coords.) Universidad de Murcia, 415-427.

GALDOS URRUTIA, R. y RUIZ URRESTARAZU, E. (2011): «Cambios demográficos en el País Vasco a inicios del siglo XXI. Un análisis comarcal». Papeles de Geografía, $\mathrm{n}^{\circ}$ 53-54, 89-105.

GARCÍA PALOMARES, J.C. y GUTIÉRREZ PUEBLA, J. (2007): «La ciudad dispersa: cambios recientes en los espacios residenciales de la Comunidad de Madrid». Anales de Geografía de la Universidad Complutense, vol. 27, $\mathrm{n}^{\circ}$ 1, 45-67.

JIMÉNEZ HERRERO, L.M. (Dir.) (2011): Sostenibilidad en España 2010. Madrid, Observatorio de la Sostenibilidad en España y Mundi-Prensa.

LUXÁN, M. y MARTÍN, U. (2012): «Demografía» en Informe socioeconómico de la C.A. de Euskadi 2012, Vitoria-Gasteiz, Eustat, 1-46.

MARMOLEJO DUARTE, C. y STALLBOHM, M. (2008): «En contra de la ciudad fragmentada: ¿hacia un cambio de paradigma urbanístico en la Región Metropolitana de Barcelona?». Scripta Nova, vol. XII, nº 270. Disponible en http://www.ub.edu/geocrit/sn/ sn-270/sn-270-65.htm

MARTORI CAÑAS, J.C. (2010): «Las consecuencias del boom inmobiliario. Cambios en la densidad de las metrópolis españolas, 2001-2007». Scripta Nova, vol. XIV, n 333. Disponible en http://www.ub.edu/geocrit/sn/sn-333.htm

MATA, R. (2007): Auge inmobiliario y evolución de los usos del suelo en España. Por una nueva cultura del Territorio. Universidad Autónoma de Madrid.

MELLA MÁRQUEZ, J.M. (2008): «Explosión de la ciudad y ordenación del territorio en España: algunos apuntes». CLM economía: Revista económica de Castilla-La Mancha, $\mathrm{n}^{\mathrm{o}} 11,165-199$.

MIRALLES-GUASCH, C. (2011): «Dinámicas metropolitanas y tiempos de la movilidad: la región metropolitana de Barcelona, como ejemplo». Anales de geografía de la Universidad Complutense, vol. $31, \mathrm{n}^{\circ} 1,125-145$.

MUÑIZ, I., CALATAYUD, D. y GARCÍA, M.A. (2007): «Sprawl. Causas y efectos de la dispersión urbana» en La ciudad de baja densidad: lógicas, gestión y contención (Indovina, F., Coord.) Diputación de Barcelona, 307-347.

MUÑOZ RAMÍREZ, F. (2008): Urbanalización: paisajes comunes, lugares globales. Barcelona, Gustavo Gili.

NAREDO PÉREZ, J.M. (2004): «Perspectivas de la vivienda». Información Comercial Española: Revista de economía, $\mathrm{n}^{\circ} 815,143-154$.

NAREDO PÉREZ, J.M. y FRÍAS SAN ROMÁN, J. (2007): «El metabolismo económico de la conurbación madrileña, 1984-2001» en La ciudad de baja densidad.Lógicas, gestión y contención (Indovina, F., Coord.) Diputació de Barcelona, 131-184.

NEL·LO, O. (2004): «¿Cambio de siglo, cambio de ciclo? Las grandes ciudades españolas en el umbral del s. XXI». Ciudad y Territorio, $\mathrm{n}^{\circ}$ 141-142, 523-542.

NEL·LO, O. (2011): «Estrategias para la contención y gestión de las urbanizaciones de baja densidad en Cataluña». Ciudad y territorio: Estudios territoriales, n ${ }^{\circ}$ 167, 81-98.

OLIVA SERRANO, J. y RIVERA, M.J. (2003): «Utopías y sentidos de habitar la ciudad dispersa: estrategias residenciales en el Área Metropolitana de Pamplona». Zainak, nº 23, 137-153. 
OLIVER, J. (2005): Demografía y vivienda en España y en las CC.AA. Colección Estudios Caixa Catalunya, Barcelona.

PALACIOS GARCÍA, A.J. (2008): «Fuentes estadísticas sobre la vivienda en España: un obstáculo para el diseño de la política de vivienda». Scripta Nova, vol. XII, n 270. Disponible en http://www.ub.edu/geocrit/sn/sn-270/sn-270-38.htm

PRADOS VELASCO, M.J. (2006): «Los parques naturales como factor de atracción de la población. Un estudio exploratorio sobre el papel de la 'naturbanización' en Andalucía». Cuadernos Geográficos, n ${ }^{\circ}$ 38, 87-110.

RODRÍGUEZ MARCOS, J. (2001): Estructura y cambios del parque residencial de la C.A. de Euskadi. Vitoria-Gasteiz, Eustat.

ROMERO GONZÁLEZ, J. (2010): «Construcción residencial y gobierno del territorio en España. De la burbuja especulativa a la recesión. Causas y consecuencias». Cuadernos Geográficos de la Universidad de Granada, $\mathrm{n}^{\circ}$ 47, 17-46.

RUIZ URRESTARAZU, E. y GALDÓS URRUTIA, R. (2009): «Revisión crítica de las Directrices de Ordenación Territorial del País Vasco» en Territorios, sociedades y politicas (Feria, T., García, A. y Ojeda, J.F., eds.) Sevilla, Universidad Pablo de Olavide-AGE, 249-262.

SANCHEZ MALDONADO, J. y SUÁREZ-PANDIELLO, J. (2008): «Hacienda local y urbanismo. ¿Es tan grave como lo pintan?». CLM economía: Revista económica de Castilla-La Mancha, $\mathrm{n}^{\circ}$ 11, 245-264.

TORRES ELIZBURU, R. (2015): «Pautas de localización residencial en el País Vasco 19912010. Algunas características socio-demográficas de las poblaciones suburbanas», Estudios Geográficos, vol. 76, n 279, 671-702.

URKIDI ELORRIETA, P. (2012): «Conceptualización de la ordenación del territorio y primeras experiencias de planificación territorial en la C.A. del País Vasco». Scripta Nova, vol. XVI, no 394. Disponible en http://www.ub.edu/geocrit/sn/sn-394.htm

URRUTIA, V. (2006): «Vivienda» en Informe socioeconómico de la C.A. de Euskadi 2006. Vitoria-Gasteiz, Eustat, 459-493.

VINUESA ANGULO, J., RIVA, J.M. y PALACIOS, A.J. (2008): El fenómeno de las viviendas desocupadas. Fundación General de la Universidad Autónoma de Madrid. Disponible en http://www.uam.es/personal_pdi/filoyletras/juvian/documentos/DOC\%20Y\%20 PUBLIC/2008\%20VIVIENDA\%20DESOCUPADA.pdf

VINUESA ANGULO, J. y MARTÍN CORTÉS, B. (2013): «La (sobre)dimensión del crecimiento residencial en Madrid. El planeamiento urbanístico como coartada». Documents d'Anàlisi Geogràfica, vol. 59, nº 1, 51-74. 
